\title{
Reforma neoliberal y política macroeconómica en el Perú
}

\section{Oscar Dancourt}

Profesor del Departamento

de Economía

de la Pontificia Universidad

Católica del Perú.
En este trabajo se describe el experimento neoliberal de los años noventa, ubicándolo en su contexto histórico. La hipótesis central es que la economía peruana de este decenio carece de un sistema operativo de políticas monetarias y fiscales, que funcione sin producir grandes trastornos en el nivel de actividad económica. La autoridad monetaria no cuenta con los instrumentos básicos que históricamente han sido usados para manejar los shocks externos adversos en la economía peruana, debido a dos reformas estructurales realizadas en el ámbito financiero: la dolarización del sistema bancario y la apertura de la cuenta de capitales. El artículo consta de siete secciones. Comienza con una breve introducción (sección I). Luego describe el experimento neoliberal de los años noventa, ubicándolo en su contexto histórico inmediato (sección II); analiza el papel que han tenido la estrategia de crecimiento, la situación económica internacional y la política macroeconómica en el desempeño de largo plazo de la economía peruana (sección III); describe la forma en que se manejaron los shocks externos adversos en el período 1950-1975 (sección IV); analiza la evolución del régimen de política macroeconómica en los años noventa, examinando sus limitaciones (sección V); ilustra estas limitaciones con la experiencia macroeconómica reciente (sección VI) y termina con algunas conclusiones (sección VII). 


\section{I}

\section{Introducción}

La expansión de la economía peruana durante los años cincuenta y parte de los sesenta, bajo una estrategia de crecimiento primario-exportadora casi pura y una ideología estatal manchesteriana, era un anacronismo en comparación con el Cono Sur latinoamericano, donde regían la sustitución de importaciones y el pensamiento original de la CEPAL.

Sólo en los años setenta el país llegó a tener una verdadera sustitución de importaciones, también en la versión más jacobina de todo el continente. Como es natural, las exportaciones de manufacturas llegaron tarde, a fines del decenio. A partir de la crisis de la deuda externa, la historia se congeló. Luego vino la hiperinflación.

La reforma neoliberal de los años noventa, llevada a cabo por el gobierno de Fujimori, se ha propuesto regresar en lo económico a los años cincuenta, al modelo primario-exportador. El control de la hiperinflación y la derrota de Sendero Luminoso son los dos activos principales de esta empresa. Algunos sugieren que un tercer activo no despreciable es el carácter autoritario del régimen político.

Los pasivos de esta empresa también son dos. Uno de ellos es el extremismo, que es casi una tradición en el Perú. En la historia de los últimos años hay demasiados experimentos económicos radicales, demasiadas reformas estructurales irreversibles. El radicalismo puede ser un pasivo de esta reforma neoliberal de los noventa, entre otras razones, porque impide la adecuación a las circunstancias externas, que siempre cambian para una economía como la peruana. Y el escenario externo de la primera mitad de este decenio fue, en conjunto, demasiado favorable.

El otro pasivo importante de la reforma neoliberal es el que tiene conexión con la política macroeconómica. La economía peruana rara vez ha calificado para ingresar al club de las economías mejor manejadas de América Latina, como Chile después de 1983, o Colombia. Pero tampoco tuvo defectos permanentes o estructurales en su régimen de política macroeconómica, es decir, en su sistema de políticas fiscales y monetarias.

Hoy día, la situación es distinta. Como se detalla más adelante, el régimen de política macroeconómica actual sufre de severas limitaciones, causadas por la liberalización financiera de los noventa: esto es, por la dolarización del sistema bancario y por la apertura de la cuenta de capitales.

\section{II}

\section{El significado de la reforma estructural de los años noventa}

Las reformas estructurales aplicadas por el gobierno de Fujimori han reimplantado una estrategia de crecimiento primario-exportadora similar a la que ha imperado en la economía peruana durante la mayor parte de su historia económica. Este parece ser el rasgo distintivo de la versión peruana del neoliberalismo frente a otros experimentos similares realizados en América Latina. ${ }^{1}$

$\square$ El autor agradece los comentarios de Waldo Mendoza; así como la asistencia prestada por Alejandro Olivares. De igual modo, agradece el apoyo financiero del Centro Internacional para el Desarrollo y la Agencia Canadiense para el Desarrollo Internacional.
Para entender la lógica de este retorno al pasado, haremos un breve recuento del crecimiento económico del Perú desde 1950 hasta la actualidad, organizado a partir de dos elementos: primero, la identificación de los períodos (periodización) por los que atravesó la evolución macroeconómica en estos 45 años y, segundo, la descripción de los principales cambios ocurridos en la estrategia de crecimiento y en la tasa de inversión en cada uno de estos períodos.

\footnotetext{
${ }^{1}$ Véanse Seminario (1995) y Schuldt (1994).
} 
Como se muestra en el gráfico 1, en la evolución de largo plazo del PIB per cápita pueden distinguirse tres grandes etapas. ${ }^{2}$ La primera etapa (1950-1975) fue un período de rápido crecimiento, interrumpido por algunas recesiones breves (las de 1958-1959 y de 19671969); el producto per cápita creció a una tasa media anual de $2.5 \%$. Esta primera etapa también fue de baja inflación para los estándares peruanos: alcanzó un promedio de $10 \%$ anual.

La segunda etapa (1976-1990), puede caracterizarse como una crisis de larga duración con ciclos violentos de recesión y auge; ${ }^{3}$ como se aprecia en el gráfico 1, a principios de los años noventa el producto per cápita había retrocedido al nivel que tenía 30 años antes. Fue también un período de alta inflación que desembocó en la hiperinflación de 1988-1990, a finales del gobierno de Alan García (1985-1990); excluyendo esos últimos tres años, la inflación media alcanzó al 83\% anual. Durante el trienio de la hiperinflación, el nivel de precios subió 39 veces por año (4 049\% anual), mientras que el producto per cápita sufrió una caída sin precedentes, de casi un tercio.

La tercera y última etapa (1991-1997) constituyó un nuevo momento de estabilización y de expansión, en que el producto per cápita se incrementó en más de 3\% anual, aunque sin sobrepasar los niveles máximos registrados previamente. La inflación exhi-

GRAFICO 1

Perú: Producto interno bruto per cápita, 1950-1997

(Indices: $1979=100$ )

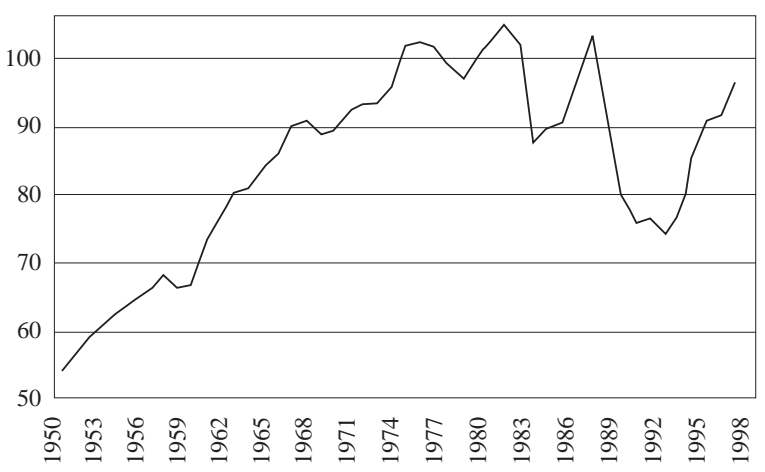

Fuente: Banco Central de Reserva del Perú.

\footnotetext{
${ }^{2}$ Para una periodización más detallada, véase Vega-Centeno (1989).

${ }^{3}$ Dos trabajos importantes sobre los ciclos y las tendencias de la economía peruana en estos 45 años, Seminario y Boullon (1992) y Robles (1996), encuentran un punto de quiebre estructural a mediados de los años setenta, a partir del cual la volatilidad de los agregados macroeconómicos se incrementó sustancialmente.
}

bió una clara tendencia decreciente, situándose por debajo del $10 \%$ anual al final de esta fase.

Cabe destacar ante todo que el modelo de desarrollo o estrategia de crecimiento que estuvo vigente durante gran parte de la primera etapa, caracterizada por una combinación de rápido crecimiento y baja inflación, fue una estrategia primario-exportadora casi pura.

La vigencia de este modelo primario-exportador, con un Estado pequeño y librecambista, se prolongó en el Perú hasta bien entrados los años sesenta. Según Thorp y Bertram (1978, parte IV, Introducción), la economía peruana 'entre 1948 y fines de los años sesenta fue el ejemplo por excelencia en América Latina de ese sueño de los desarrollistas ortodoxos: un sistema liderado por las exportaciones en el cual la entrada de capital extranjero y la repatriación de las utilidades fuesen virtualmente irrestrictas y la intervención del gobierno se mantuviese a un nivel mínimo.'

Esta experiencia peruana era un anacronismo en el Cono Sur de Latinoamérica, ${ }^{4}$ donde imperaban el modelo de industrialización mediante la sustitución de importaciones, mercados internos protegidos e inflaciones relativamente altas, y donde el sector primarioexportador era uno de los menos dinámicos de la economía. 5

El ocaso de este modelo primario-exportador se produjo a pesar de su buen desempeño macroeconómico. La crisis del Estado oligárquico ${ }^{6}$ en el Perú se inició tardíamente con el primer gobierno de Belaúnde (1963-1968), quien modificó parcialmente dicho modelo al poner en marcha una industrialización sustitutiva de las importaciones (ISI) de carácter moderado, que atrajo cierta inversión extranjera. ${ }^{7}$

Posteriormente, con el régimen militar del General Velasco Alvarado (1968-1975), el modelo primario-exportador ${ }^{8}$ fue reemplazado realmente por la ISI.

\footnotetext{
${ }^{4}$ Según Borricaud (1989), la oligarquía peruana "había aprendido a preservar su posición dominante en un mundo y en una región en los cuales sus equivalentes extranjeros habían ya perdido mucho de su poder anterior".

5 Véase Hofman (1993).

${ }^{6}$ Cotler (1994) dice que esta crisis ocurrió cuando "la participación política tendió a extenderse por todo el país y en todos los niveles sociales". En "estas circunstancias, la estructura de la propiedad agraria y el capital extranjero, ejes del régimen de dominación, fueron cuestionados".

${ }^{7}$ Schydlowsky (1995) lo explica porque esta industrialización se inició al amparo de una combinación específica de fuerte protección arancelaria y débil "protección" cambiaria.

${ }^{8}$ Como han señalado R. Thorp (1995, cap. IV) y Fitzgerald (1985), esta nueva estrategia de crecimiento no descuidó la expansión de las exportaciones de materias primas.
} 
La estrategia de industrialización se radicalizó, tanto en términos del grado de protección del mercado interno como del grado de intervención del Estado en la economía. ${ }^{9}$ A través de la nacionalización de una fracción considerable de la inversión extranjera, y de la estatización de una parte de los activos de la oligarquía, se constituyó un fuerte sector de empresas públicas que llegó a controlar más del 30\% del PIB. Según Fitzgerald (1985), "el Estado se hizo responsable de las tres cuartas partes de las exportaciones, la mitad de las importaciones, más de la mitad de la inversión fija, dos terceras partes del crédito bancario y una tercera parte de todo el empleo en el sector empresarial".

El otro punto que cabe destacar, entonces, es que hubo modificaciones notables en la estrategia de crecimiento durante la primera etapa, caracterizada por un rápido crecimiento y una baja inflación. Este buen desempeño macroeconómico fue compatible tanto con el modelo primario-exportador como con el modelo de sustitución de importaciones.

En la segunda etapa, caracterizada por un prolongado estancamiento y una inflación alta y creciente, no ocurrió cambio decisivo alguno en el modelo de desarrollo impuesto por las reformas estructurales de Velasco Alvarado. Dos rasgos claves de esta estrategia de crecimiento persistieron durante estos quince años: la importancia de las empresas públicas y la fuerte protección a la industria manufacturera.

Hubo dos intentos importantes de alterar este modelo de desarrollo, que fracasaron finalmente. El primero estuvo vinculado al programa de fomento de las exportaciones manufactureras que se aplicó en 1977-1980. El segundo tuvo por eje la apertura comercial de 1979-1982.

Según Schydlowsky (1986), el auge de las exportaciones no tradicionales en 1977-1980 debe atribuirse a 'la combinación de sustanciales apoyos a las exportaciones (un promedio de $27 \%$ del valor FOB), una devaluación real (de $28 \%$ entre 1976 y 1978), y un mercado interno que se encogía (se redujo $20 \%$ o más entre 1976 y 1978). En 1979 se aprobó una nueva ley de incentivos para los productos no tradicionales, con el compromiso de mantenerla incólume durante los siguientes 10 años. Se creyó que por fin había llegado la hora de la exportación no tradicional. Nadie sospechaba en ese momento que el nuevo gobierno civil que

${ }^{9}$ Véanse Thorp (1995), Fitzgerald (1985) y Schydlowsky y Wicht (1979). asumiría el poder a mediados de 1980 revertiría la política antes de transcurridos seis meses.'

Además de eliminar este exitoso programa de promoción de exportaciones no tradicionales, el segundo gobierno de Belaúnde (1980-1985) profundizó la apertura comercial $^{10}$ iniciada en 1979 por el régimen militar de Morales Bermúdez (1976-1980) y generó un retraso cambiario significativo. La crisis de balanza de pagos de 1982-1983, asociada al inicio de la crisis de la deuda externa, terminó con este primer experimento de liberalización de las importaciones, que fue el antecedente más directo de la reforma neoliberal de los noventa.

En la tercera y última fase, con el gobierno de Fujimori, la estrategia de crecimiento volvió a alterarse radicalmente. Las reformas estructurales del decenio de 1990 pueden entenderse como una antítesis casi perfecta de las del gobierno de Velasco Alvarado (1968-1975), o como una reedición de las que realizara el gobierno de Odría (1948-1956).

Con la privatización de las empresas públicas, y con una apertura comercial unilateral extremadamente radical, ${ }^{11}$ se retornó de hecho al modelo primarioexportador de los cincuenta. La industria manufacturera perdió importancia de manera visible y ramas enteras de la estructura industrial desaparecieron. Un indicador de este proceso de desindustrialización fue el siguiente: en 1995 el PIB recuperó finalmente el nivel absoluto que había alcanzado en 1987, sin embargo, la producción manufacturera ${ }^{12}$ fue casi $20 \%$ menor.

El capital extranjero, orientado al sector extractivo exportador y a los servicios públicos, recuperó un papel muy destacado en la economía al adquirir una buena parte de las empresas estatales privatizadas. ${ }^{13} \mathrm{El}$

\footnotetext{
10 Véanse Ferrari (1992) y Rojas (1996).

${ }^{11} \mathrm{El}$ sistema de protección paraarancelaria de la industria manufacturera se desmanteló íntegramente y el arancel en cascada o escalonado, típico de la ISI, fue reemplazado por un arancel plano al estilo chileno. Entre 1990 y 1993, el promedio arancelario pasó del 66 al 16\%; el 98\% del valor importado pagaba en 1993 una tarifa del 15\% (véanse Rojas, 1996; Ferrari, 1992; Rossini, 1991). Además, debido al arancel externo común escalonado que se adoptó, el Perú suspendió su participación en el Pacto Andino (véanse Vega, 1997 y Fairlie, 1996).

12 Definida como la industria manufacturera no procesadora de recursos primarios, lo que excluye las ramas vinculadas directamente a la exportación de materias primas (refinación de metales, elaboración de harina de pescado, etc.). Al respecto, véase Banco Central de Reserva del Perú (1996). Sobre la desindustrialización, véase Jiménez (1996).

${ }^{13}$ Entre 1991 y 1993, el fisco obtuvo muy poco por la venta de empresas públicas. Los ingresos por privatizaciones adquirieron significación a partir de 1994, al venderse 29 empresas por un valor equivalente al $35 \%$ de los ingresos tributarios anuales del gobierno
} 
cierre de toda la banca estatal de fomento, que tenía una importante participación en los mercados de crédito y depósitos, también debe incluirse en la lista de las principales reformas. ${ }^{14}$

Es ilustrativo comparar el modelo impuesto por Odría con el instaurado cuatro décadas después por Fujimori. Entre los rasgos comunes, González (1994) señala la apertura comercial y de la cuenta de capitales, y un Estado con mínima participación en la economía, que incentiva la inversión extranjera, especialmente en el sector exportador de materias primas y en los servicios públicos, mediante una legislación muy favorable; entre las diferencias, menciona el peso significativo en las cuentas fiscales y externas que tiene ahora, y que no tuvo antes, la deuda pública externa.

En realidad, la gran diferencia es que las exportaciones reales todavía no se han expandido en la magnitud requerida. La promesa de grandes expansiones de las exportaciones mineras en el último quinquenio de los noventa se ha convertido en el punto de apoyo teórico del modelo de crecimiento de Fujimori. Pero, hasta ahora, la palanca real que ha permitido el crecimiento económico durante 1993-1995 ha sido una enorme afluencia de capitales (de corto plazo y para privatizaciones) sin precedentes en los últimos 45 años.

Una manera de apreciar esta diferencia se muestra en el gráfico 2. Allí se observan dos hechos. Primero, que la balanza comercial durante el gobierno de Odría alternó los déficit y los superávit, resultando en promedio un saldo equilibrado; mientras que durante el gobierno de Fujimori se registra un déficit comercial cada vez mayor, equivalente al $20 \%$ de las exportaciones anuales medias. Segundo, que la balanza comercial y las reservas de divisas del sistema bancario, medidas ambas como porcentaje de las exportaciones, se han movido casi siempre en la misma dirección durante los 45 años considerados..$^{15} \operatorname{Los}$ años 19911997 constituyen la única excepción prolongada a esta regla. La importancia de la afluencia de capitales es

central. En 1995, la venta de otras 28 empresas y activos diversos generó un monto igual al 12\% de los ingresos tributarios. En 1996, los ingresos alcanzados en 28 privatizaciones se elevaron nuevamente hasta representar un $25 \%$ de la recaudación tributaria. En 1997, estos ingresos por privatizaciones se redujeron en más del $70 \%$ respecto al año anterior, alcanzando un $6 \%$ de la recaudación tributaria, y se estima que en 1998 caerán todavía más. La aceptación de títulos de la deuda pública externa como medio de pago en el proceso privatizador ha sido una excepción.

14 Véase Rojas y Vilcapoma (1996).

${ }^{15}$ Esto sugiere que era el sector real de la economía el que gobernaba el ritmo al que el sistema bancario acumulaba activos externos. notoria durante la primera mitad de los años noventa. Esto ha permitido que las reservas de divisas suban notablemente, a pesar de un déficit comercial que crece y un mayor servicio de la deuda externa.

¿Cuál ha sido el comportamiento de la inversión en cada una de estas tres grandes etapas? El gráfico 3 muestra la inversión bruta total como porcentaje del PIB entre 1950 y 1997. Simplificando la periodización de Seminario y Boullon (1992), pueden identificarse cinco grandes ciclos a lo largo de estos 45 años. Un primer ciclo de inversión (minería y agricultura de exportación) se dio en 1950-1960, asociado a las reformas estructurales de Odría.

GRAFICO 2

Perú: Balanza comercial y variación de las reservas internacionales, $1950-1998^{a}$

(Porcentaje de las exportaciones de bienes)

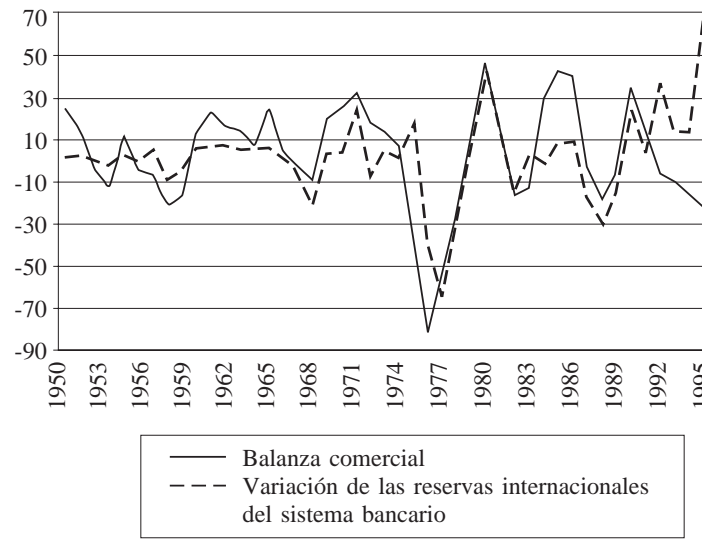

Fuente: Banco Central de Reserva del Perú (varios números). Hasta septiembre de 1998.

GRAFICO 3

Perú: Formación bruta de capital fijo, 1950-1997

(Porcentaje del PIB)

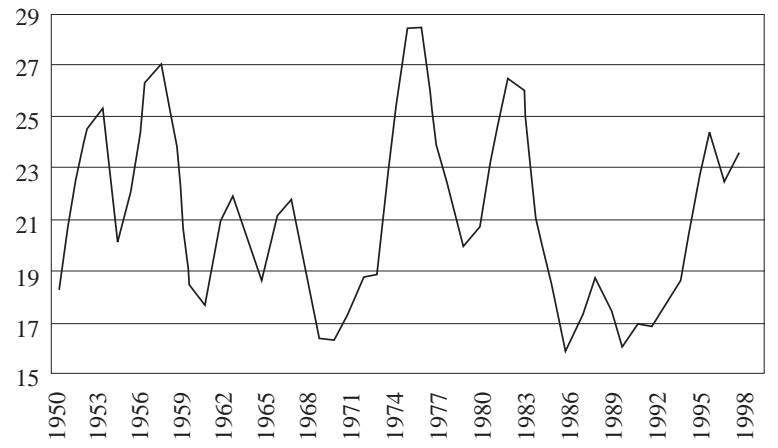

Fuente: Banco Central de Reserva del Perú. 
El segundo ciclo de inversión, que abarcó desde 1960 hasta principios del decenio de 1970, se caracterizó por un descenso claro de la tasa de acumulación de capital; una causa probable fue la incertidumbre causada por la crisis política del Estado oligárquico. ${ }^{16}$

El tercer ciclo de inversión, que se inició con el gobierno de Velasco Alvarado y terminó con la crisis de la deuda externa en 1982, se distinguió por el rol básico que desempeñó en él la inversión pública financiada con deuda externa. Este proceso de acumulación estatal se interrumpió en 1976-1977 a raíz de una crisis precoz de deuda externa, asociada al fin de la 'era dorada ${ }^{17}$ de la economía mundial; la resolución de esta crisis con un notable incremento de las exportaciones ${ }^{18}$ permitió que la inversión pública se recuperara al principio del segundo gobierno de Belaúnde. Los problemas de balanza de pagos de 1982-1983, vinculados a otro shock externo, cerraron definitivamente este ciclo.

El cuarto ciclo (1983-1993) trajo consigo el desplome total de la tasa de inversión. La carga de la deuda externa sobre las cuentas fiscales, la inestabilidad macroeconómica creciente y la hiperinflación desata- da por la política económica del gobierno de García (1985-1990) tras el intento fallido de estatización de la banca, fueron causas importantes de esta caída de la inversión. Hay que subrayar, sin embargo, que la guerra interna desatada en 1980 también parece haber sido un factor básico que destruyó poco a poco la confianza del sector privado y aumentó la incertidumbre extraeconómica, o riesgo político, a grados extremos. Esto hizo que la inversión privada se contrajese persistentemente, mientras crecía la expatriación de capitales. $^{19}$

El quinto y último ciclo de inversión se inició en 1993, apoyado por una masiva afluencia de capitales vinculada a la privatización de empresas públicas y a la repatriación de capitales nacionales. Una hipótesis sostiene que la captura de Abimael Guzmán, el líder de Sendero Luminoso, fue el acontecimiento que permitió el inicio de este ciclo al reducir exponencialmente el riesgo político. La hipótesis alternativa propone darle el crédito de esta nueva bonanza de inversión al programa de estabilización y reformas estructurales llevado a cabo por el gobierno de Fujimori.

\section{III}

\section{Interpretaciones del crecimiento peruano}

Existen tres interpretaciones básicas de esta evolución de la economía peruana entre 1950 y 1995 . La primera atribuye este desempeño, bueno o malo, a la estrategia de crecimiento que imperó en cada período. Por ejemplo, quienes advierten que parte importante del buen desempeño macroeconómico de la primera etapa se dio bajo un modelo primario-exportador, o que casi la totalidad del desastroso desempeño macroeconómico de la segunda etapa ocurrió bajo un modelo de sustitución de importaciones con una fuerte intervención estatal, están tentados de convertir esta asociación en causalidad. El modelo de desarrollo, es decir, las

\footnotetext{
16 Véase Cotler (1994).

17 Véase Maddison (1991).

18 A fines de los años setenta maduraron dos grandes proyectos de inversión, en cobre y petróleo, iniciados al principio del gobierno de Velasco Alvarado, se elevó la relación de precios del intercambio, y hubo un auge de las exportaciones no tradicionales.
}

reformas estructurales de uno u otro signo, explicarían el desempeño macroeconómico de largo plazo. ${ }^{20}$

La segunda interpretación atribuye este comportamiento histórico de la economía peruana a las fluctuaciones recurrentes de la economía internacional, particularmente pronunciadas desde mediados de los setenta. ${ }^{21}$ Así, quienes adviertan que el total de ese buen desempeño macroeconómico de la primera etapa coincide casi exactamente con el contexto externo extremadamente favorable que creó la 'era dorada' del capitalismo occidental descrito por Maddison (1992),

\footnotetext{
19 Véase Figueroa (1993).

${ }^{20}$ Desde una perspectiva proindustrialista, Schydlowsky y Wicht (1979) y Jiménez (1991) enfatizan el límite intrínseco a una industrialización dependiente de insumos y bienes de capital importados, y orientada exclusivamente al mercado interno. Paredes y Sachs (1990) y Hunt (1996) adoptan una perspectiva antiindustrialista.

21 Véase Krugman (1988).
} 
podrían concluir con igual razón que esta situación económica internacional es lo que explicaría tal desempeño. $^{22}$

Desde este punto de vista, también se podría argüir que el estancamiento y la alta inflación de los ochenta fueron fruto de otro shock externo adverso, similar al que marcó el fin de la 'era dorada' y desencadenó la crisis de la deuda externa. O también podría afirmarse que la afluencia de capitales ocurrida en la primera mitad de los años noventa, asociada a tasas de interés externas históricamente bajas, ${ }^{23}$ fue decisiva para que se dé el nuevo momento de estabilización de los precios y expansión del producto agregado que tipificó la primera mitad de los años noventa en toda América Latina.

La tercera interpretación de esta experiencia histórica le otorga un papel protagónico a la política macroeconómica; ${ }^{24}$ el éxito o el fracaso dependerían de las políticas macroeconómicas adoptadas a lo largo del tiempo. Como afirman Marfán y Bosworth (1994) al evaluar la experiencia chilena, cuyo éxito tiende normalmente a asociarse con reformas estructurales, 'lo que emerge — particularmente al evaluar los acontecimientos económicos de los últimos diez años- es el claro beneficio de las políticas macroeconómicas convencionales que hacen hincapié en los precios estables y el crecimiento estable de la demanda.'

Un ejemplo clásico es el papel que desempeñó la política macroeconómica en Europa durante la 'era dorada'. Según Maddison (1991), el principal logro de la política gubernamental no fue 'la sintonía fina' sino el 'éxito en alimentar un auge de la demanda que mantuvo a las economías en una zona de empleo alto. El sesgo en pro del crecimiento y el empleo, y la ausencia de políticas deflacionarias con efectos burdamente perversos, fueron las características que más diferenciaron la política interna de posguerra de aquella de preguerra. Los logros fueron mayores de lo que era razonable esperar. La falta de riesgos recesivos en términos de producción y la persistencia de utilidades satisfactorias gatillaron un auge secular de la inversión.'

En particular, habría que destacar la importancia que tienen las políticas macroeconómicas adoptadas como reacción ante los recurrentes shocks externos que sufre una economía como la peruana. De esta interacción entre política macroeconómica y shocks externos resultan las crisis de balanza de pagos o los ajustes exitosos, eventos singulares que muchas veces determinan la trayectoria posterior de la economía en términos de crecimiento e inflación.

Como señala Krugman (1988), 'un país que sufre shocks externos severos puede considerarse afortunado si sólo debe soportar una recesión temporal y un episodio de inflación, y no una reducción persistente de sus expectativas de crecimiento y un traslado permanente a tasas de inflación más altas.' Y agrega que la respuesta de política macroeconómica es 'la clave para encarar con éxito un shock externo adverso.'

Así, por ejemplo, quien advierta que el punto de inflexión del desempeño macroeconómico peruano (el año 1975) coincide no sólo con un shock externo, sino también con una modificación significativa del régimen de política macroeconómica, ${ }^{25}$ podría sentirse tentado a extender las conclusiones de Marfán y Bosworth al caso del Perú. De esta manera, podría argüirse que la inflación y el estancamiento que caracterizaron la segunda etapa (la de 1975-1990), se explican por la interacción de los shocks externos adversos y de esta modificación al régimen de política macroeconómica. ${ }^{26}$

En suma, una conclusión prudente sería que los resultados macroeconómicos de largo plazo no sólo dependen de la estrategia de crecimiento, sino que también del contexto internacional y de la política macroeconómica.

\footnotetext{
22 Iguíniz (1986), Frenkel, Fanelli y Rosenwurcel (1993) y Taylor (1991), han hecho hincapié en la importancia del contexto externo como factor determinante del desempeño macroeconómico. Hofman (1993) muestra que el crecimiento del PIB per cápita bajo el modelo ISI fue alto en Latinoamérica durante la era dorada.

${ }^{23}$ Véase Calvo, Leiderman y Reinhart (1993).

${ }^{24}$ Véase Thorp (1995), donde se subraya el papel de la gestión macroeconómica.
}

\footnotetext{
${ }^{25}$ A mediados de los años setenta, se sustituyó el sistema de tipo de cambio fijo por un tipo de cambio móvil con una meta de tipo de cambio real, y se hizo de los precios públicos un instrumento privilegiado de la política fiscal. Véanse Thorp (1995) y Fitzgerald (1985).

${ }^{26}$ Para cerrar las brechas externa y fiscal generadas por el aumento de la carga de la deuda externa, se utilizaron como instrumentos el tipo de cambio y los precios públicos. Primero, sus valores reales se elevaron fuertemente; luego, sus valores nominales fueron indexados a la inflación pasada.
} 


\section{IV}

\section{Fluctuaciones económicas y shocks externos}

Tanto los estudios históricos ${ }^{27}$ como los econométricos ${ }^{28}$ sugieren que un componente esencial del modo de regulación macroeconómico vigente durante el período 1950-1990, fue la particular mezcla de políticas fiscales, crediticias y cambiarias que se aplicaban en respuesta a un shock externo adverso o desestabilizador (caída de la relación de precios del intercambio, subida de la tasa de interés internacional). Normalmente, esta mezcla de políticas incluía una devaluación, una restricción crediticia y una política fiscal contractiva.

Esta forma de administración de los shocks externos adversos y ciertos rasgos estructurales de la economía peruana han dado lugar a un conjunto de regularidades empíricas o hechos estilizados de la dinámica de corto plazo. Estos hechos están vinculados a las relaciones existentes entre el ciclo de corto plazo del nivel de actividad económica, la tasa de inflación y la evolución del sector externo (tipo de cambio, balanza comercial y reservas de divisas).

El punto principal es que los períodos de recesión son a la vez períodos de aceleración inflacionaria, ${ }^{29}$ y de crisis de balanza de pagos. Es necesario subrayar que las características básicas de esta dinámica de corto plazo, en particular de la cadena crisis de balanza de pagos-aceleración de la inflación-recesión, son un rasgo común a las tres etapas en que hemos dividido estos 45 años.

La cadena señalada tiene varios eslabones. El primer eslabón conecta las devaluaciones ${ }^{30}$ con una caída apreciable de las reservas de divisas del sistema bancario. La regularidad de este hecho refleja una regla de política vigente durante estos 45 años, una función de reacción invariante de las autoridades mone-

\footnotetext{
${ }^{27}$ En Thorp (1996), véase un análisis detallado de todas las experiencias de estabilización peruanas desde los años cincuenta.

${ }^{28}$ Véanse Seminario y Boullon (1992), Robles (1996), Terrones y Calderón (1993) y Vilcapoma (1996).

${ }^{29}$ Una regularidad empírica notable de la economía peruana es que las aceleraciones de la inflación coinciden con las recesiones. Tres trabajos recientes sobre la experiencia peruana - Seminario y Boullon (1992), Terrones y Calderón (1993) y Robles (1996), que usan distintos métodos para separar el ciclo de la tendencia- encuentran que la inflación es anticíclica respecto al nivel de actividad económica.

${ }^{30}$ Las devaluaciones durante el período 1950-1975, o el incremento de la tasa de devaluación durante el período 1976-1995.
}

tarias, ya que el tipo de cambio siempre ha sido administrado, de una u otra manera, por el Banco Central.

El segundo eslabón surge de comprobar que el inicio de todas las recesiones importantes durante estos 45 años (que podemos fechar convencionalmente en 1953, 1957, 1967, 1975, 1982 y 1987) coincide o es precedido por una caída de las reservas, debida a un déficit de la balanza comercial; ${ }^{31}$ no se registran caídas de reservas internacionales generadas exclusivamente por salidas de capitales. De las seis recesiones enumeradas, las cinco primeras coinciden con shocks externos adversos. ${ }^{32}$ Dos de ellas, la de 1975 y la de 1982, estuvieron asociadas a crisis de la deuda pública externa (reducción de desembolsos y alza de la tasa de interés internacional). ${ }^{33}$

El tercer eslabón de la cadena es la comprobación de que durante estos 45 años no existe, prácticamente, ningún episodio importante de aceleración inflacionaria que no haya estado asociado a una devaluación o a un incremento de la tasa de devaluación.

Resumiendo esta dinámica de corto plazo, podemos decir que durante el período de tipo de cambio nominal fijo (1950-1975), las recesiones estuvieron asociadas a caídas de reservas y a devaluaciones discretas, de una sola vez, que produjeron aceleraciones transitorias de la inflación. Una vez resuelta la crisis de balanza de pagos, la inflación se redujo. ${ }^{34}$

Varios son los factores que estarían gobernando esta dinámica de corto plazo. El primero es esa regla de política invariante que estipula que las autoridades sólo devalúan el tipo de cambio cuando las reservas de divisas disminuyen. El segundo, es que una elevación del tipo de cambio real puede ser recesiva e

\footnotetext{
31 Véase Vilcapoma (1996). La balanza comercial puede deteriorarse por shocks externos y/o por factores internos. Lo que deseamos recalcar es que si el déficit comercial, cualquiera sea su origen, implica que las reservas de divisas disminuyen, con esto inicia un ciclo recesivo. Durante los años noventa, debido a la afluencia de capitales, han coexistido un déficit comercial creciente, una reactivacion del nivel de actividad económica, y un aumento de las reservas de divisas.

32 Véase Dancourt, Mendoza y Vilcapoma (1997).

33 Véase Ugarteche (1996) y Cline (1981).

${ }^{34}$ Por el contrario, cuando se intenta fijar el tipo de cambio real y los precios públicos reales (grosso modo, el período 1976-1990), una vez resuelta la crisis de balanza de pagos, la inflación no disminuye.
} 
inflacionaria en el corto plazo al estilo del modelo de Taylor-Krugman (veáse Krugman y Taylor (1978). El tercero, es que la elevación del tipo de cambio real ha sido normalmente parte de un paquete de medidas para enfrentar una crisis de balanza de pagos; este paquete incluye, por lo general, políticas fiscales y crediticias restrictivas. ${ }^{35}$

En el cuadro 1 se presentan las correlaciones entre las tasas de crecimiento del PIB agregado, con diferentes rezagos y adelantos, y las tasas de crecimiento de un conjunto de variables macroeconómicas (precios, tipo de cambio, gasto publico, crédito, balanza comercial, etc.). Este cuadro permite clasificar las distintas variables macroeconómicas como procíclicas o anticíclicas respecto al PIB, según el coeficiente de correlación sea de signo positivo o negativo. Como es poco apropiado intentar captar la estructura de rezagos y adelantos de las distintas variables macroeconómicas respecto al PIB empleando datos anuales, nos referiremos sólo a las correlaciones contemporáneas.
Estos coeficientes de correlación entre las tasas de crecimiento del PIB y de las diversas variables macroeconómicas cubren todo el período 1950-1996, sin distinguir fases de auge o recesión, y resumen en un sólo número el tipo y el grado de la asociación de las fluctuaciones del nivel de actividad con estas variables.

En términos generales, el cuadro 1 confirma los principales hechos estilizados que hemos descrito anteriormente. Un primer resultado es que la inflación y la devaluación son claramente anticíclicas (suben en la recesión y bajan en el auge). Un segundo resultado es que el gasto público y el crédito reales son altamente procíclicos (suben en el auge y bajan en la recesión). Un tercer resultado es que las importaciones y la capacidad de importación son claramente procíclicas, mientras que la balanza comercial es anticíclica ${ }^{36}$ (se deteriora en el auge y mejora en la recesión). Finalmente, obtenemos que los tributos son procíclicos, y que el superávit fiscal primario del gobierno central es acíclico. ${ }^{37}$

CUADRO 1

Correlación entre las tasas de crecimiento del PIB

y de otras variables macroeconómicas, 1950-1996

\begin{tabular}{|c|c|c|c|c|c|c|c|c|}
\hline \multirow{3}{*}{$\begin{array}{l}\text { Tasa de } \\
\text { crecimiento }\end{array}$} & \multirow{3}{*}{$\begin{array}{c}\text { Desviación } \\
\text { estándar } \\
\text { relativa }^{a}\end{array}$} & \multirow{3}{*}{$\begin{array}{c}\text { Desviación } \\
\text { estándar }\end{array}$} & \multirow{3}{*}{$\begin{array}{c}\text { Autocorre- } \\
\text { laciones }\end{array}$} & \multicolumn{5}{|c|}{ Coeficientes de correlación } \\
\hline & & & & \multicolumn{2}{|c|}{ Rezagos } & \multirow[b]{2}{*}{0} & \multicolumn{2}{|c|}{ Adelantos } \\
\hline & & & & -2 & -1 & & 1 & 2 \\
\hline $\mathrm{G}^{\mathrm{b}}$ & 3.0 & 15.7 & $0.44 *$ & 0.08 & $0.48 * *$ & $0.62 * *$ & $0.45 * *$ & 0.11 \\
\hline $\mathrm{T}^{\mathrm{c}}$ & 2.7 & 13.8 & $0.33 *$ & -0.30 & 0.11 & $0.64 * *$ & $0.50 * *$ & $0.42 * *$ \\
\hline $\mathrm{L}^{\mathrm{d}}$ & 4.0 & 20.9 & $0.41 * *$ & -0.24 & 0.15 & $0.58 * *$ & 0.30 & 0.23 \\
\hline $\mathrm{P}^{\mathrm{e}}$ & 234.1 & 1217.1 & 0.36 & -0.28 & $0.53 * *$ & $-0.44 * *$ & -0.20 & -0.21 \\
\hline $\mathrm{E}^{\mathrm{f}}$ & 139.1 & 723.2 & 0.15 & -0.20 & $-0.35^{*}$ & $-0.47 * *$ & $-0.34 *$ & -0.27 \\
\hline $\mathrm{E} / \mathrm{P}^{\mathrm{g}}$ & 4.2 & 21.7 & $-0.42 *$ & 0.12 & $0.42 * *$ & -0.03 & $-0.32 *$ & 0.05 \\
\hline $\mathrm{X}^{\mathrm{h}}$ & 1.8 & 9.6 & 0.00 & -0.01 & 0.01 & 0.23 & 0.12 & $0.46^{* *}$ \\
\hline $\mathrm{M}^{\mathrm{i}}$ & 3.0 & 15.7 & 0.27 & -0.18 & $0.41 * *$ & $0.65 * *$ & 0.12 & -0.21 \\
\hline $\mathrm{CM}^{\mathrm{j}}$ & 6.0 & 31.2 & $-0.30 *$ & $-0.31 *$ & 0.09 & $0.43 * *$ & 0.00 & 0.08 \\
\hline \multicolumn{9}{|l|}{ Niveles } \\
\hline $\mathrm{T}-\mathrm{G}^{\mathrm{k}}$ & & & 0.24 & $-0.35^{*}$ & -0.05 & 0.24 & $0.36^{*}$ & 0.38 \\
\hline $\mathrm{X}-\mathrm{M}^{\mathrm{l}}$ & & & $0.56^{*}$ & -0.23 & $-0.53 * *$ & $-0.30 *$ & 0.15 & 0.24 \\
\hline A-RIN ${ }^{m}$ & & & $0.32 *$ & $-0.14 * *$ & -0.19 & 0.14 & 0.19 & $0.44 * *$ \\
\hline
\end{tabular}

Fuente: Dancourt, Mendoza y Vilcapoma (1997).

* Significativo al $95 \%$.

** Significativo al $99 \%$.

a Razón entre la desviación estándar de la variable y la del PIB.

b Gasto real del gobierno central.

c Ingresos tributarios reales del gobierno central.

d Crédito total real del sistema bancario al sector privado.

e Indice de precios al consumidor.

35 Los trabajos de Seminario y Boullon (1992), Robles (1996), Terrones y Calderón (1993) y Vilcapoma (1996) encuentran que el tipo de cambio real es anticíclico, que los salarios reales son procíclicos, y que el crédito al sector privado es procíclico y mucho más volátil que el PIB. Vilcapoma (1996) muestra también que algunos componentes del gasto público son procíclicos. f Tipo de cambio nominal al fin del período.

g Tipo de cambio real al fin del período.

$\mathrm{h}$ Exportaciones reales.

i Importaciones reales.

j Indice de la capacidad de importación.

$\mathrm{k}$ Ahorro en cuenta corriente sin ingresos de capital.

l Balanza comercial.

$\mathrm{m}$ Flujo de reservas internacionales del sistema bancario.

\footnotetext{
${ }^{36}$ El carácter anticíclico de la balanza comercial opera con un período de rezago (primero sube el PIB y luego se deteriora la balanza comercial, y viceversa).

37 Esperábamos que fuese procíclico, es decir, desestabilizador. Véase Gavin, Hausmann, Perotti y Talvi (1997).
} 
Entre los resultados anómalos (respecto a esta caracterización del auge y la recesión que planteamos), tenemos, en primer lugar, que el tipo de cambio real es acíclico $^{38}$ contemporáneamente. En segundo lugar, que las variaciones de las reservas internacionales de divisas del sistema bancario son acíclicas contemporáneamente. Quizás esto refleje que los auges no tienen un patrón tan sistemático o regular como las recesiones.

\section{$\mathrm{V}$}

\section{Estabilización y dolarización}

Aun cuando sea posible hoy día aplicar una réplica fiel de la estrategia de crecimiento de 40 años atrás, no se puede hacer lo mismo en el terreno de la política macroeconómica. La idea básica de esta sección es que la mezcla de políticas utilizada en la primera etapa (la de 1950-1975) para manejar con éxito los shocks externos adversos, no se puede aplicar en los años noventa.

Como veremos, la liberalización financiera de los noventa ha trabado el mecanismo tradicionalmente usado en la economía peruana para enfrentar un shock externo, al disminuir notablemente la potencia de la política monetaria: el Banco Central es hoy incapaz de imponer una restricción crediticia y tampoco puede devaluar fácilmente.

Durante el gobierno de Fujimori pueden identificarse dos grandes regímenes de política macroeconómica. En el primer régimen (1990-1992), la mezcla de política macroeconómica estuvo compuesta por una meta monetaria (el Banco Central reguló la cantidad de dinero interno en circulación a través de la compraventa de dólares) y una fijación activa de los precios públicos, que fue el instrumento privilegiado de la política fiscal.

En este régimen hubo una clara división del trabajo entre la política monetaria y la política fiscal. La política monetaria se encargaba indirectamente del control de la inflación, fijando tasas decrecientes de incremento de la cantidad de dinero. La política fiscal generaba un superávit primario destinado a cumplir con los pagos de la deuda externa, elevando los precios públicos reales de los combustibles. ${ }^{39}$

\footnotetext{
${ }^{38}$ Creemos que esto tiene relación, en parte, con la definición de tipo de cambio real utilizada, que no incorpora la inflación internacional. Es claro, sin embargo, que todas las recesiones ocurridas entre 1950 y 1996 empezaron con un alza del tipo de cambio real.

${ }^{39}$ Existió un interregno, en la segunda mitad de 1990, en el cual la política antiinflacionaria consistió en fijar el tipo de cambio y los precios públicos nominales, al estilo de los planes heterodoxos de los años ochenta, de la experiencia boliviana de 1985, o de la experiencia argentina con Cavallo. Véase Dancourt (1996).
}

La política monetaria restrictiva provocaba una apreciación cambiaria que, a su turno, frenaba el alza del nivel de precios; sin embargo, el incremento de los precios públicos actuaba en la dirección contraria. Esta dualidad explica que la desinflación en 1990-1992 fuese lenta y exhibiese retrocesos pronunciados, asociados a notables fluctuaciones de la tasa de devaluación y a frecuentes shocks de precios públicos. Aun así, esta experiencia ha servido para confirmar una vez más la eficacia antiinflacionaria que tiene en el Perú una sobrevaluación del tipo de cambio.

El proceso de control de la hiperinflación en el Perú ha sido notablemente lento, cuando se le compara con procesos similares en economías también dolarizadas, como la boliviana (1985) o la argentina (1991). Desde el inicio del programa de estabilización hasta que se registró una inflación (precios al consumidor) por debajo del $2 \%$ mensual durante tres meses consecutivos, la estabilización peruana tardó 37 meses (de agosto de 1990 a septiembre de 1993), la argentina cuatro meses (abril de 1991 a agosto de 1991) y la boliviana 13 meses (agosto de 1985 a septiembre de 1986).

Tal combinación de políticas sirvió, sin embargo, para conciliar el proceso de desinflación con el incremento del servicio de la deuda externa, cosa que no se pudo hacer en los años ochenta. Los dos objetivos inmediatos del programa económico del gobierno de Fujimori eran acabar con la hiperinflación y normalizar las relaciones del país con la comunidad financiera internacional. Esto último supuso reanudar el servicio de la deuda pública externa (gráfico 4), primero a los organismos multilaterales, luego a los gobiernos agrupados en el Club de París y, por último, a la banca comercial internacional en el marco del Plan Brady.

El período de vigencia de esta mezcla de políticas, como se puede ver en el cuadro 2, se caracteriza por una lenta desinflación, por el estancamiento del nivel de actividad económica en el fondo del pozo, y por una enorme sobrevaluación del tipo de cambio real. 
GRAFICO 4

\section{Perú: Servicio pagado de la deuda pública, 1987-1997 \\ (Porcentaje de las exportaciones de bienes)}

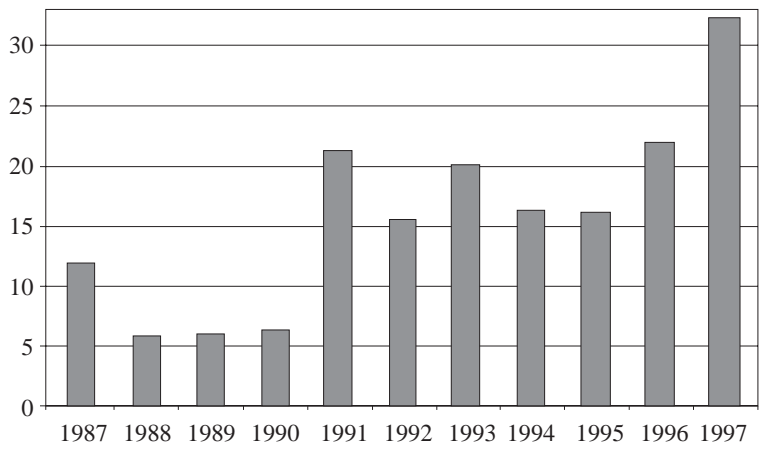

Fuente: Banco Central de Reserva del Perú (varios números).

La mecánica de esta apreciación del tipo de cambio real puede resumirse así. De un lado, a través de la compra de dólares, la política monetaria fija una cierta tasa de aumento de la cantidad de dinero interno. Del otro lado, la política fiscal impulsa la tasa de inflación por encima del crecimiento de la cantidad de dinero, a través de reajustes periódicos de los precios públicos. De esta manera, se reduce la cantidad real de dinero.

Dado el nivel de actividad, esto implica que al público le falta dinero nacional (el medio de cambio) para realizar sus transacciones. Con miras a conseguirlo, el público puede inmediatamente vender dólares (el de- pósito de valor por excelencia en una economía dolarizada como la peruana) o, a mediano plazo, cambiar sus hábitos de uso del dinero, acostumbrándose a realizar cada vez más transacciones directamente en dólares. ${ }^{40}$

La hipótesis de este artículo es que la primera reacción fue la fuerza principal que provocó la sobrevaluación cambiaria. Como puede verse en el gráfico 5, la mayor parte del retraso cambiario que distingue al gobierno de Fujimori se produjo al iniciarse el programa de estabilización; en agosto de 1990 el nivel general de precios se quintuplicó, debido a que el gobierno elevó el precio de los combustibles en 30 veces, la base monetaria real se redujo en dos tercios y el tipo de cambio libre real bajó a la mitad respecto del mes anterior.

Posteriormente, a este factor se sumó el impacto más gradual del ingreso de capitales externos, que presionó el tipo de cambio a la baja, alterando la oferta relativa de soles y dólares. ${ }^{41}$

En el segundo régimen de política macroeconómica (1993-1995), la mezcla de políticas se modificó.

\footnotetext{
${ }^{40}$ Ciertamente, también puede demandar más crédito bancario, o rematar sus inventarios de bienes. Lo primero no es una objeción esencial para el argumento del texto, y lo segundo no se ha observado en la economía peruana.

${ }^{41}$ Ruiz (1995) contrasta econométricamente ambas hipótesis (política monetaria vs. afluencia de capitales), y concluye apoyando la visión de una apreciación cambiaria generada directamente por la política monetaria.
}

CUADRO 2

Perú: Indicadores macroeconómicos, 1991 a 1997

(Variación anual)

\begin{tabular}{|c|c|c|c|c|c|c|c|}
\hline & 1991 & 1992 & 1993 & 1994 & 1995 & 1996 & 1997 \\
\hline Sector no primario ${ }^{\mathrm{a}}$ & 3.6 & -1.7 & 6.2 & 14.1 & 9.5 & 1.7 & 9.7 \\
\hline Sector primario ${ }^{b}$ & 1.85 & -5.1 & 8.0 & 11.6 & 2.3 & 4.6 & 4.7 \\
\hline PIB & 2.9 & -2.8 & 6.5 & 13.1 & 7.0 & 2.6 & 7.4 \\
\hline Demanda interna menos importaciones & 2.0 & -3.1 & 7.5 & 11.7 & 7.0 & -0.3 & 4.6 \\
\hline Inversión pública & 6.4 & 13.9 & 12.8 & 21.9 & 14.5 & -8.5 & 9.0 \\
\hline Exportaciones & 6.0 & 2.5 & 3.3 & 17.5 & 7.0 & 11.4 & 16.3 \\
\hline Déficit de la balanza comercial ${ }^{\mathrm{c}}$ & -8.3 & -9.7 & -17.0 & -21.3 & -38.8 & -33.9 & -30.5 \\
\hline Indice PIB $(1987=100)$ & 79.8 & 78.4 & 83.3 & 94.3 & 100.8 & 103.0 & 111.2 \\
\hline Inflación & 139.2 & 56.7 & 39.5 & 15.4 & 10.2 & 11.8 & 6.5 \\
\hline Devaluación & 85.9 & 69.8 & 31.9 & 1.4 & 6.5 & 12.1 & 4.7 \\
\hline Precio de los combustibles & 114.1 & 42.5 & 41.7 & 4.4 & 6.3 & 32.2 & 23.4 \\
\hline Crédito total al sector privado & 284.8 & 96.4 & 74.0 & 65.0 & 43.6 & 49.6 & 30.1 \\
\hline
\end{tabular}

Fuente: Banco Central de Reserva del Perú (1995 y 1998).

a Comprende industria no procesadora de bienes primarios, construcción, gobierno, comercio y resto.

b Comprende agricultura, pesca, minería y manufactura procesadora de recursos primarios.

c Como porcentaje de las exportaciones. 
GRAFICO 5

Perú: Tipo de cambio real, enero 1989-julio 1998 (Agosto de 1990=100)

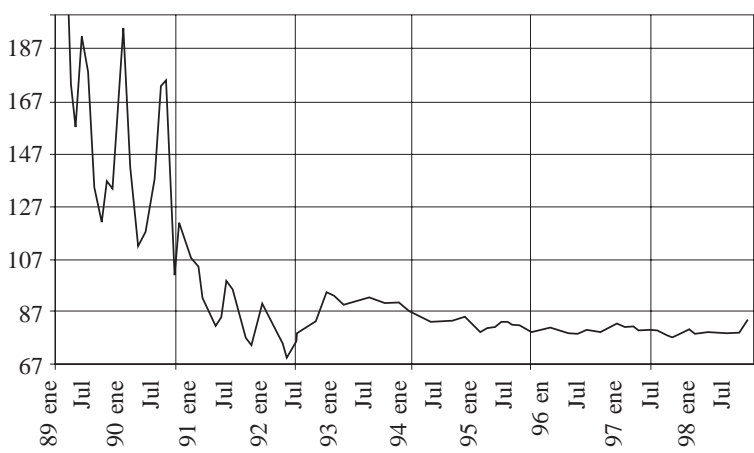

Fuente: Banco Central de Reserva del Perú (varios números).

Para explicar el cambio del régimen anterior a éste habría que tomar en cuenta, primero, que los ingresos públicos por privatizaciones adquirieron significación a partir de 1993-1994 y, segundo, que Fujimori deseaba la reelección en los comicios de 1995.

El precio real de los combustibles disminuyó paulatinamente y el gasto público pasó a ser el instrumento privilegiado de la política fiscal. Las metas monetarias fueron sustituidas por metas cambiarias, que redujeron apreciablemente la banda de fluctuación del tipo de cambio, hasta aproximarse a un tipo de cambio fijo. Un indicador de esta transición podría ser la volatilidad relativa ${ }^{42}$ del tipo de cambio respecto a la cantidad de dinero: ésta pasó de 2.34 en 1991-1992 a 0.21 en 1993-1995.

Como se muestra en el cuadro 2, el período de vigencia de esta segunda mezcla de políticas se caracterizó por una rápida desinflación -asociada a la cuasi fijación del tipo de cambio y los precios públicos nominales-, por una notable reactivación de la actividad económica, vinculada a la política fiscal expansiva, y por un grado mucho menor de apreciación del tipo de cambio real. De esta manera se cerró el ciclo inflacionario iniciado a mitad de los años setenta.

En ambos períodos, la afluencia de capitales permitió que las reservas de divisas aumentaran a pesar del creciente déficit comercial, generando así una vía de escape al conflicto entre estabilidad de precios y

\footnotetext{
${ }^{42}$ Es decir, la desviación estándar de la devaluación mensual dividida por la desviación estándar del crecimiento mensual de la base monetaria.
}

equilibrio externo que ha caracterizado a la economía peruana en estos 45 años. (Si el tipo de cambio se usa para frenar el alza de los precios, se deteriora la balanza comercial, y viceversa.) Es claro que esta sobrevaluación cambiaria -y su impacto antiinflacionario- no hubiese perdurado sin la afluencia de capitales externos.

De esta breve descripción se podría concluir que el régimen de política macroeconómica y la tasa de inflación del período 1993-1997 se han aproximado bastante al sistema de tipo de cambio fijo y al $10 \%$ de inflación anual, observados durante el apogeo del modelo primario-exportador.

Esta aproximación, sin embargo, es más aparente que real. Como hemos mencionado, la mezcla de políticas crediticias y cambiarias que servía en los años cincuenta y sesenta para encarar los shocks externos, no puede utilizarse en los noventa. Básicamente, porque dos reformas estructurales asociadas a la liberalización financiera - la dolarización del sistema bancario y la apertura de la cuenta de capitales - impiden que la política monetaria opere adecuadamente.

Para entender este resultado, conviene describir el marco institucional en el que opera la política monetaria. En el sistema financiero peruano no existe un mercado de deuda o bonos públicos y la bolsa de valores tiene escasa importancia macroeconómica. Más bien, el sistema bancario y un mercado cambiario, de dólares, extenso y bien organizado, son las dos instituciones centrales del sistema financiero.

Estas dos instituciones básicas se han combinado de diversas maneras desde 1980 hasta la actualidad. Durante el gobierno de Belaúnde (1980-1985), el sistema bancario aceptó depósitos y otorgó préstamos en moneda nacional y en moneda extranjera, se aplicó un esquema de minidevaluaciones, y el tipo de cambio libre siguió estrechamente al tipo de cambio oficial.

En los primeros años del gobierno de García (1985-1987), el sistema bancario se desdolarizó, se aplicó un sistema de tipo de cambio fijo múltiple, y el tipo de cambio libre mantuvo un diferencial estable respecto al tipo de cambio oficial más alto. Posteriormente, entre 1988 y 1990, la hiperinflación provocó la dolarización de la riqueza financiera del sector privado, que esta vez ocurrió fuera del sistema bancario; el tipo de cambio oficial perdió progresivamente toda significación, y el mercado cambiario se expandió notablemente, consolidando al dólar como el principal activo de reserva de la economía peruana. 
Finalmente, con el gobierno de Fujimori, la banca de fomento fue cerrada, la banca comercial privada volvió a ser autorizada para aceptar depósitos y otorgar préstamos en moneda extranjera, y se instauró un régimen de tipo de cambio flexible. En la actualidad, las tres cuartas partes de los créditos y los depósitos están dolarizados, y el régimen cambiario, como ya hemos mencionado, tiende a aproximarse cada vez más a un sistema de tipo de cambio fijo, aunque sin ningún compromiso explícito de parte de la autoridad monetaria. ${ }^{43}$

Esta última dolarización del sistema bancario es el resultado conjunto de esa autorización y de la flotación cambiaria. Con esta flotación, el Banco Central adquirió la capacidad de controlar la cantidad de dinero nacional en circulación. Este control, a su vez, impidió que el sector privado pudiese remonetizarse automáticamente, desatesorando la moneda extranjera acumulada durante la hiperinflación una vez que ésta terminó, como suele ocurrir en un sistema de tipo de cambio fijo.

Por lo tanto, los dólares billetes se dirigieron hacia los bancos, en vez de cambiarse por soles. Introducir el dólar en el sistema bancario implicó asociar a la moneda extranjera con la economía de costos de transacción que caracteriza a un sistema de pagos ban- cario, además de convertirlo en un activo que rinde interés.

Se produjo, entonces, un masivo incremento de los depósitos en dólares, como puede apreciarse en el cuadro 3. Tres fuentes pueden dar cuenta de este incremento. Primero, el ingreso al sistema bancario nacional ("bancarización") de los dólares billetes atesorados durante la hiperinflación. Segundo, la repatriación de capitales y el ingreso de capitales de corto plazo de no residentes. Tercero, los préstamos obtenidos en el exterior por la banca comercial local desde fines de 1994. Cabe anotar que los ingresos de divisas generados por la privatización de empresas públicas (cuya contrapartida, en su mayor parte, es inversión extranjera directa) no constituyen una cuarta fuente, pues estos dineros se mantienen fuera del país y del sistema bancario nacional; ${ }^{44}$ sólo lo serían si el gobierno financiara sus gastos con la venta de estos dólares al público.

Las consecuencias de este proceso de dolarización de los depósitos en las relaciones de la banca comercial con sus deudores y con el Banco Central han sido de muy largo alcance.

El incremento de los depósitos en dólares permitió, primero, una significativa expansión del crédito bancario al sector privado. Segundo, debido aparente-

CUADRO 3

Perú: Indicadores monetarios, 1990 a $1997^{a}$

\begin{tabular}{|c|c|c|c|c|c|c|c|c|c|c|c|}
\hline \multirow{4}{*}{ Años } & \multirow{4}{*}{$\begin{array}{c}\text { Base } \\
\text { monetaria } \\
(1989=100)\end{array}$} & \multicolumn{9}{|c|}{ Banca comercial } & \multirow{4}{*}{$\begin{array}{c}\text { Reservas } \\
\text { internacionales } \\
\text { del sistema bancario } \\
\text { (millones de } \\
\text { dólares) }\end{array}$} \\
\hline & & \multicolumn{2}{|c|}{$\begin{array}{c}\text { Depósitos en } \\
\text { moneda extranjera }\end{array}$} & \multicolumn{2}{|c|}{$\begin{array}{c}\text { Créditos en } \\
\text { moneda extranjera }\end{array}$} & \multirow{3}{*}{$\begin{array}{c}\text { Pasivos } \\
\text { internacionales } \\
\text { (\% de créditos } \\
\text { en moneda } \\
\text { extranjera) }\end{array}$} & \multicolumn{4}{|c|}{$\begin{array}{l}\text { Tasa de interés } \\
\text { real anual }\end{array}$} & \\
\hline & & \multirow{2}{*}{$\begin{array}{l}\text { Miles de } \\
\text { millones de } \\
\text { dólares }\end{array}$} & \multirow{2}{*}{$\begin{array}{c}\% \text { del } \\
\text { total de } \\
\text { depósitos }\end{array}$} & \multirow{2}{*}{$\begin{array}{l}\text { Miles de } \\
\text { millones de } \\
\text { dólares }\end{array}$} & \multirow{2}{*}{$\begin{array}{l}\% \text { del } \\
\text { total de } \\
\text { créditos }\end{array}$} & & \multicolumn{2}{|c|}{$\begin{array}{l}\text { Moneda } \\
\text { extranjera }\end{array}$} & \multicolumn{2}{|c|}{$\begin{array}{l}\text { Moneda } \\
\text { nacional }\end{array}$} & \\
\hline & & & & & & & Activa & Pasiva & Activa & Pasiva & \\
\hline 1990 & 69 & 0.756 & 63 & 0.451 & 64 & 15 & & & & & 531 \\
\hline 1991 & 56 & 2.163 & 75 & 1.242 & 68 & 7 & -10.0 & -19.4 & 43.9 & -29.6 & 1304 \\
\hline 1992 & 58 & 2.627 & 75 & 1.755 & 76 & 13 & 26.3 & 13.7 & 72.0 & -24.2 & 2174 \\
\hline 1993 & 56 & 3.875 & 82 & 2.732 & 79 & 14 & 9.0 & -0.07 & 23.6 & -18.2 & 2793 \\
\hline 1994 & 72 & 5.280 & 77 & 3.308 & 74 & 15 & 1.0 & -8.0 & 20.5 & -7.0 & 4737 \\
\hline 1995 & 89 & 6.090 & 74 & 5.426 & 71 & 19 & 13.2 & 2.5 & 21.1 & -0.3 & 6693 \\
\hline 1996 & 79 & 8.007 & 75 & 7.268 & 74 & 23 & 17.1 & 6.0 & 16.8 & -1.2 & 8862 \\
\hline 1997 & 85 & 8.976 & 73 & 8.537 & 77 & 28 & 13.7 & 3.5 & 22.5 & 3.2 & 7963 \\
\hline
\end{tabular}

Fuente: Banco Central de Reserva del Perú (varios números).

a Datos de fin de período.

\footnotetext{
${ }^{43}$ La flotación cambiaria ocupa todavía un lugar destacado en la retórica de las autoridades económicas peruanas.
}

\footnotetext{
${ }^{44}$ A fines de 1996, estos fondos representaban el 37\% de las reservas de divisas del Banco Central de Reserva del Perú.
} 
mente al deseo de los bancos de atar activos y pasivos por tipo de moneda para evadir el riesgo cambiario, esta expansión crediticia ha generado una dolarización de la deuda de las empresas no financieras (cuadro 3).

Tercero, el incremento de los depósitos bancarios en moneda extranjera ha supuesto una ganancia considerable de reservas internacionales netas para el Banco Central, a través del alto encaje promedio aplicado a estos depósitos; a fines de 1996, estos encajes representaban el $40 \%$ de las reservas de divisas de la autoridad monetaria. Sin embargo, este arreglo institucional también implica lo contrario, esto es, que una corrida contra los depósitos bancarios en dólares es, automáticamente, una corrida contra las reservas del Banco Central.

Cuarto, este proceso ha alterado radicalmente los términos en que el Banco Central debe cumplir su rol de prestamista de última instancia, ante la eventualidad de una corrida de los depositantes, nacionales o extranjeros; de tal modo que ahora las reservas de divisas del Banco Central no sólo cumplen la tradicional función de proveer liquidez internacional para amortiguar los impactos de los diversos shocks externos a los que está expuesta la economía peruana, sino que, además, constituyen la garantía última de la estabilidad del sistema bancario nacional. ${ }^{45}$

En este marco institucional, la política monetaria opera a través del mercado de dólares y a través del sistema bancario. Actualmente, los principales instrumentos de la política monetaria son la intervención en el mercado cambiario (la compraventa de dólares, que se puede usar para regular la cantidad de dinero o para fijar el tipo de cambio), los encajes obligatorios sobre los depósitos bancarios, la tasa de interés o remuneración al encaje que el Banco Central abona a los bancos comerciales, y los activos financieros (antes depósitos, hoy valores emitidos por el propio Banco Central) que la autoridad monetaria puede ofrecer a los bancos comerciales.

Dado este contexto institucional, el tipo de cambio y la oferta de crédito bancario son las dos grandes correas de transmisión que vinculan la política moneta-

\footnotetext{
45 Según Seminario (1995), "la dolarización ha generado un régimen monetario que combina los sistemas de tipo de cambio libre y fijo. El Banco Central emite, en realidad, dos monedas. La primera [los depósitos bancarios en dólares] mantiene una paridad fija con el dólar y tiene un respaldo de $100 \%$ en activos internacionales. La otra moneda es el sol peruano, que mantiene una paridad libre con el dólar."
}

ria con el nivel de actividad económica, la balanza comercial y la inflación. ${ }^{46}$

Sin embargo, la dolarización del sistema bancario y la libre movilidad de capitales han reducido notablemente la potencia de la política monetaria, al trabar estos dos grandes canales de transmisión. En primer lugar, la autoridad monetaria no puede regular la oferta de crédito agregada, cualquiera sea el régimen cambiario.

Si el Banco Central está dispuesto a dejar flotar limpiamente el tipo de cambio, la política monetaria (a través de la compraventa de dólares y/o los papeles del Banco Central) podría regular la base monetaria y la oferta de crédito bancario en moneda nacional; es decir, en el mejor de los casos, sólo una cuarta parte de la oferta de crédito total. Dada la dolarización, el problema es que el Banco Central no tiene cómo regular el volumen de crédito en dólares, que representa las tres cuartas partes de la oferta total, sin limitar de alguna manera la libre movilidad de capitales. ${ }^{47}$

En segundo lugar, la dolarización del sistema bancario también traba el otro canal de transmisión de la política monetaria, que opera a través del tipo de cambio. Bajo estas condiciones, las empresas y familias que obtienen sus ingresos en soles tienen su deuda denominada en dólares. Acéptese que el Banco Central puede apreciar el tipo de cambio real, elevando el precio nominal del dólar. En consecuencia, una devaluación implica elevar la tasa real de interés y la carga real de la deuda.

Dada la inflación, el costo promedio real del crédito o la carga real de la deuda dependen directamente de las tasas de interés en dólares (que siguen a las internacionales, dados los encajes y el riesgo país), de la tasa de devaluación, y de las tasas de interés en soles, así como de las fracciones del crédito que se otorga en soles y dólares. El hecho estilizado es que la tasa activa real promedio sigue estrechamente a la tasa de devaluación, como se muestra en el gráfico 6.

De esta manera, una mididevaluación o maxidevaluación puede incrementar abruptamente la cartera

\footnotetext{
46 Seminario (1995) y Dancourt y Mendoza (1996) presentan modelos con estas características. Ruiz (1995), utilizando la técnica de vectores autorregresivos (VAR), concluye que "el principal canal de transmisión de los cambios de la emisión pareciera ser el tipo de cambio y no la tasa de interés".

47 Ciertamente, si se desdolarizara el sistema bancario, el Banco Central podría regular la oferta de crédito agregado adoptando una flotación cambiaria, sin necesidad de interferir en la libre movilidad de capitales.
} 
GRAFICO 6

Perú: Tasa de interés real activa y tasa de devaluación, enero 1993-julio 1998 (Tasas anuales; promedio móvil de tres meses)

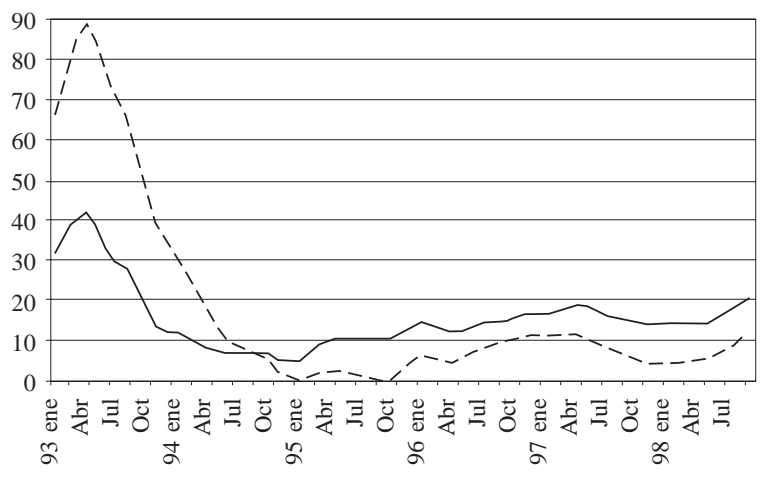

--- Devaluación $\longrightarrow$ Tasa de interés real

Fuente: Banco Central de Reserva del Perú (varios números).

morosa de los bancos, amenazando con inducir una crisis bancaria. Este efecto de una eventual maxidevaluación ha fortalecido notablemente la coalición de intereses que se opone a ella, incorporando a los bancos y a sus deudores. La fuerza de esta coalición, y el temor de agravar un desequilibrio externo con una crisis bancaria, impiden que el Banco Central utilice el tipo de cambio, como se hacía en 1950-1975.

En suma, la autoridad monetaria de los años noventa no puede restringir el crédito ni tampoco puede devaluar fácilmente de manera significativa.

En realidad, el problema es más complejo todavía, porque la política fiscal del Perú en los noventa es poco flexible, debido a la magnitud del servicio de la deuda pública externa. Supóngase que el pago neto por deuda externa (servicio de la deuda menos desembolsos nuevos) es positivo, que la recaudación tributaria depende del nivel de actividad, y que la regla de política es que el superávit fiscal primario sea igual al pago neto de la deuda externa pública. En estas condiciones, en las cuales el gobierno no recibe préstamos del sistema bancario interno, el gasto fiscal deja de ser un instrumento de política y se convierte en una variable de ajuste o endógena. Es decir, el gasto público dependerá directamente del nivel de actividad económica e inversamente de la carga real de la deuda; y esta última, a su vez, dependerá directamente tanto de la tasa de interés internacional como del tipo de cambio real.

Dadas las tasas impositivas, este sistema fiscal no sólo constituye un poderoso canal de transmisión de los shocks externos (por ejemplo, si sube la tasa de interés internacional, cae el gasto público), sino que además funciona como un desestabilizador automático. Cuando el nivel de actividad baja por cualquier motivo y disminuye la recaudación tributaria, el gasto público también se reduce, y refuerza así el impulso recesivo inicial. Ya no se puede elevar el gasto público para impedir el inicio de un ciclo recesivo. Ni tampoco para contrarrestar el impacto de una devaluación (si es que ésta es recesiva, porque baja el salario real y/o eleva la tasa de interés real), o el de una política crediticia restrictiva.

Si el gasto público incluye, por ejemplo, el seguro de desempleo, el sistema funciona como un estabilizador automático. El gasto sube cuando el nivel de actividad cae, y viceversa. Este sistema supone que el déficit (o superávit) fiscal primario es una variable de ajuste libre, es decir, cuyo valor no es fijado exógenamente por los requerimientos de pago de la deuda.

Ciertamente, en el corto plazo, el uso de los recursos de la privatización ${ }^{48}$ - o un mayor endeudamiento externo- puede impedir la operación de este desestabilizador automático, dejando abierta la puerta para aumentar el gasto público cuando el nivel de actividad cae. Pero la trayectoria futura del servicio de la deuda externa pública sugiere que esta situación no se resolverá fácilmente. ${ }^{49}$

Así, el conjunto factible de mezclas de políticas macroeconómicas queda severamente restringido. Este es un defecto estructural del régimen de política macroeconómica actual, si se admite que el manejo normal de la coyuntura económica —y no sólo la administración de los shocks externos adversos- debiera estar a cargo de la política monetaria, antes que de la política fiscal, por su mayor flexibilidad y menor potencia relativa.

\footnotetext{
48 A fines de 1996, estos recursos equivalían al 40\% de los ingresos fiscales anuales.

49 Véase Ugarteche (1996).
} 


\section{VI}

\section{El efecto tequila (1995) y la crisis rusa (1998)}

La descripción de estas dos coyunturas macroeconómicas marcadas por una crisis financiera permite identificar la naturaleza de las conexiones que la economía peruana mantiene actualmente con los mercados financieros internacionales, y también ilustrar cómo operan algunos nervios centrales del régimen de política macroeconómica vigente y cuáles son sus limitaciones.

A mediados de 1995, se interrumpió bruscamente el ciclo de expansión que venía experimentando la economía peruana desde 1993. La tasa de crecimiento del sector no primario ${ }^{50}$ de la economía, que es el que responde a las políticas fiscales y monetarias, cayó abruptamente hasta un $1.7 \%$ en 1996 , después de registrar un $9.5 \%$ en 1995 (cuadro 2). En contraste, el sector primario, que engloba a la agricultura y las actividades exportadoras de materias primas, y cuyo nivel de producción está determinado básicamente por factores de oferta, aceleró su ritmo de crecimiento entre 1995 y 1996: desde 2,3\% hasta 4,6\% por año.

La interrupción de este ciclo de crecimiento no fue causada por un shock externo adverso - el efecto tequila- como ocurrió en la Argentina. Es cierto que en el primer trimestre de 1995 se registraron todos los síntomas de una salida de capitales de corto plazo, aunque sin la virulencia observada en otros lugares de América Latina. Disminuyeron los depósitos en moneda extranjera, cayeron las reservas de divisas del sistema bancario, subieron las tasas de interés en dólares, se desplomó la bolsa de valores, y el Banco Central tuvo que asumir su rol de prestamista de última instancia de la banca comercial e intervenir en el mercado cambiario.

Sin embargo, esta salida de capitales de corto plazo no tuvo mayor efecto sobre la economía. Básicamente, porque no provocó una subida apreciable del tipo de cambio real, ni tampoco una disminución de la oferta de crédito bancario. Como hemos visto, éstas son las dos correas de transmisión que vinculan la política monetaria y las crisis financieras, con el sector real de la economía.

Esta debilidad del efecto tequila puede explicarse, primero, por las características del sistema finan-

\footnotetext{
${ }^{50} \mathrm{El}$ sector no primario agrupa a la manufactura no procesadora de recursos primarios, la construcción, el comercio y otros.
}

ciero peruano. Como no existe un mercado de títulos públicos y la bolsa de valores es pequeña, Lima no fue una plaza financiera internacional capaz de atraer alguna porción significativa de los capitales de corto plazo de no residentes que se dirigían a los mercados latinoamericanos en la primera mitad de los noventa. Presumiblemente, éstos eran los capitales sensibles a la tasa de interés estadounidense, o a eventos como la crisis mexicana de fines de 1994.

En segundo lugar, es probable que la mayor parte de las entradas de capitales de corto plazo a la economía peruana ocurridas hasta 1994, deban clasificarse como una repatriación de capitales. Estos capitales no son, en realidad, capitales de corto plazo volátiles. El asunto es que las consideraciones políticas de largo plazo - la derrota de los movimientos subversivospueden tener mucho peso en la decisión de repatriar o no capitales.

Es decir, un sistema financiero de carácter bancario y un flujo de capitales poco sensible a las tasas de interés externas, determinaron que la economía peruana permaneciese relativamente desconectada de los mercados financieros estadounidenses, a pesar de que el programa neoliberal peruano abrió radicalmente la cuenta de capitales a inicios de los noventa. Esto explica que no hubiera efecto tequila en el Perú. A diferencia de Chile, donde fue fruto de un designio de política, en el Perú esta desconexión relativa de los mercados financieros internacionales fue producto de las circunstancias. ${ }^{51}$

Como muestra el gráfico 7, la década de 1990 está marcada por una gran afluencia de capitales que se acentuó justamente durante el trienio 1994-1996. Así, el enfriamiento económico de 1996 coincidió con un enorme ingreso de capitales del orden del $80 \%$ de las exportaciones. Este ingreso de capitales de corto y largo plazo sólo disminuyó de manera apreciable re-

\footnotetext{
${ }^{51}$ Estas circunstancias están cambiando aceleradamente, desde 1995, con el creciente endeudamiento externo de corto plazo de la banca comercial local. Este proceso, que se describe más adelante, fortalece los vínculos entre la tasa de interés externa y el costo y la disponibilidad del crédito interno, por un lado, y el tipo de cambio, por el otro. Véase un análisis de los distintos efectos de un alza de la tasa de interés externa en un sistema bancario dolarizado, en Dancourt y Mendoza (1996).
} 
cientemente, en 1997. De igual manera, en el gráfico 8 se muestra que las reservas internacionales del sistema bancario crecieron aceleradamente desde 1994 hasta principios de 1997, cuando se estabilizaron alrededor de los 8500 millones de dólares.

La interrupción de la reactivación económica fue obra exclusiva de un violento viraje de la política fiscal, que se inició a mediados de 1995 y se acentuó en 1996. El origen último de este viraje puede encontrarse en la Carta de Intención que el gobierno suscribió con el Fondo Monetario Internacional (FMI) en 1995, comprometiéndose en ella a enfriar activamente la economía.

En el cuadro 2 se pudo apreciar que el desplome de la tasa de crecimiento de la economía peruana

GRAFICO 7

Perú: Flujo neto de capitales: total y de corto plazo, 1987-1997

(Porcentaje de las exportaciones de bienes)

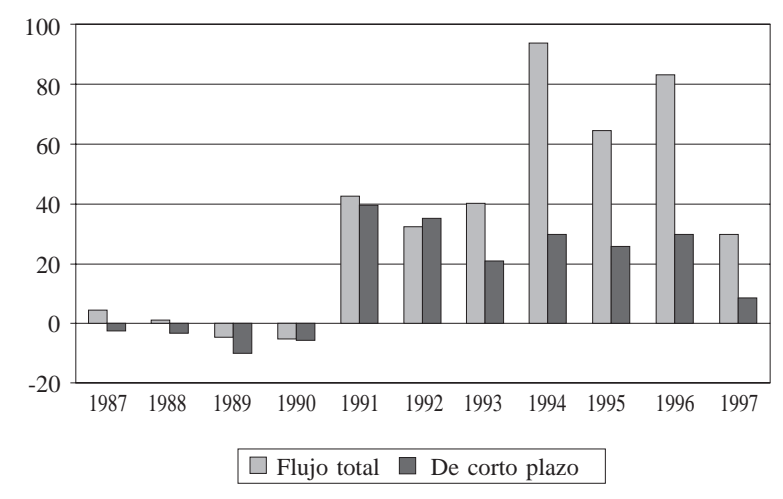

Fuente: Banco Central de Reserva del Perú (varios números).

GRAFICO 8

Perú: Reservas internacionales netas del sistema bancario, enero 1994-julio 1998 (Millones de dólares)

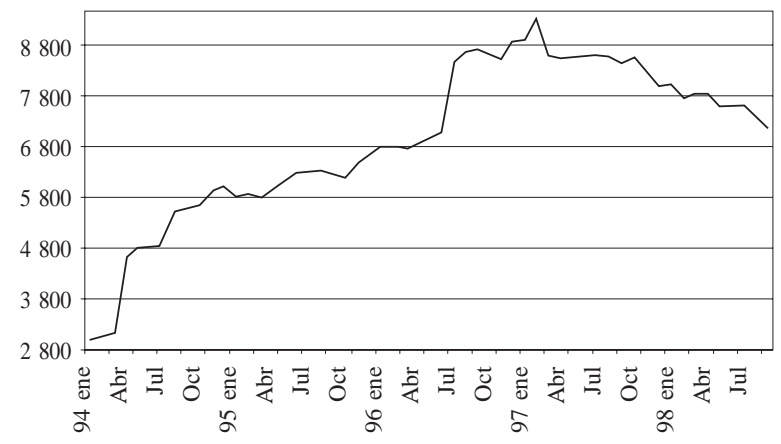

Fuente: Banco Central de Reserva del Perú (varios números). durante 1996 se originó en la contracción absoluta de la demanda interna menos importaciones. De los componentes de la demanda interna, el que tiene un comportamiento más volátil es, paradójicamente, la inversión pública que decreció en $8.5 \%$ durante 1996, después de incrementarse un $15 \%$ el año anterior. El otro indicador de la severidad del ajuste presupuestario es que el superávit fiscal primario del sector público aumentó significativamente, a pesar del enfriamiento de la economía (cuadro 4).

Tres factores pueden explicar este viraje. Primero, la crisis mexicana convenció al FMI que un déficit comercial persistente podía ser peligroso, si era financiado con capitales que podían abandonar el país de improviso; la conclusión de política fue que se necesitaba enfriar la economía para reducir el desequilibrio comercial. El segundo factor estuvo vinculado al ciclo político del gasto público: tras la reelección de Fujimori a principios de 1995, no hubo mayores resistencias gubernamentales a un recorte de tal gasto. Pero - lo que no es menos importante- las cuentas fiscales tenían que adaptarse al aumento del servicio de la deuda externa, derivado de los acuerdos realizados en 1995-1996 con los gobiernos acreedores agrupados en el Club de París, y con la banca privada internacional en el marco del Plan Brady. ${ }^{52}$

El plan era que el enfriamiento de la economía se conseguiría con un fuerte ajuste fiscal, secundado por una política monetaria restrictiva. Sin embargo, como se pudo ver en el cuadro 2, lo que realmente ocurrió fue que la política fiscal recesiva, cuyo instrumento principal fue el recorte de la inversión pública en infraestructura, estuvo acompañada de una gran expansión del crédito, que se produjo contra la voluntad explícita de la autoridad monetaria.

La política monetaria aplicada en 1995-1996 sólo podría calificarse de restrictiva si nos guiamos exclusivamente por la conducta de los agregados monetarios en moneda nacional; el hecho principal es que la tasa de incremento de la base monetaria descendió del $28 \%$ en 1995 al $7 \%$ en 1996. Sin embargo, en una economía dolarizada donde las tres cuartas partes del crédito y de los depósitos del sistema bancario están en moneda extranjera, éste es un hecho relativo. Así, la oferta total de crédito al sector privado se expandió a tasas crecientes, pasando del $43.6 \%$ en 1995 al $49.6 \%$ en 1996, debido a los mayores préstamos en moneda extranjera.

\footnotetext{
52 Véase Ugarteche (1996) y (1997).
} 
CUADRO 4

Perú: Indicadores fiscales de las operaciones del sector público no financiero (SPNF), 1991 a 1998

(Porcentaje del PIB)

\begin{tabular}{|c|c|c|c|c|c|c|c|c|c|c|c|}
\hline \multirow[t]{3}{*}{ Años } & \multicolumn{5}{|c|}{ Ahorro en cuenta corriente } & \multicolumn{2}{|c|}{ Gastos de capital } & \multirow{3}{*}{$\begin{array}{c}\text { Resultado } \\
\text { primario } \\
\text { del } \\
\text { SPNF }^{\mathrm{a}}\end{array}$} & \multirow{3}{*}{$\begin{array}{l}\text { Ingresos } \\
\text { de capital } \\
\text { del SPNF }\end{array}$} & \multirow{3}{*}{$\begin{array}{c}\text { Resultado } \\
\text { primario } \\
\text { del } \\
\text { SPNF }^{b}\end{array}$} & \multirow{3}{*}{$\begin{array}{c}\text { Gasto no } \\
\text { financiero } \\
\text { del } \\
\text { gobierno } \\
\text { central }\end{array}$} \\
\hline & \multicolumn{3}{|c|}{$\begin{array}{c}\text { Del gobierno central } \\
\end{array}$} & \multirow{2}{*}{$\begin{array}{c}\text { Del } \\
\text { SPNF }\end{array}$} & \multirow{2}{*}{$\begin{array}{c}\text { Sin } \\
\text { intereses } \\
\text { del SPNF }\end{array}$} & \multirow{2}{*}{$\begin{array}{l}\text { Inversión } \\
\text { pública }\end{array}$} & \multirow{2}{*}{$\begin{array}{c}\text { Total } \\
\text { del } \\
\text { SPNF }\end{array}$} & & & & \\
\hline & Ingresos & Gastos & Ahorro & & & & & & & & \\
\hline 1991 & 9.5 & 9.6 & -0.1 & 1.0 & 4.4 & 2.7 & 3.8 & 0.7 & 0.1 & 0.8 & 10.0 \\
\hline 1992 & 11.4 & 11.6 & -0.3 & 1.1 & 5.1 & 3.1 & 4.2 & 0.9 & 0.4 & 1.3 & 10.0 \\
\hline 1993 & 11.3 & 11.1 & 0.2 & 1.9 & 5.5 & 3.4 & 4.4 & 1.1 & 0.4 & 1.5 & 10.7 \\
\hline 1994 & 12.9 & 12.2 & 0.7 & 2.7 & 6.1 & 3.9 & 5.1 & 1.0 & 4.5 & 5.5 & 12.7 \\
\hline 1995 & 13.6 & 13.2 & 0.4 & 2.1 & 5.3 & 4.0 & 5.0 & 0.3 & 1.6 & 1.9 & 13.8 \\
\hline 1996 & 14.2 & 12.7 & 1.6 & 3.4 & 5.7 & 3.8 & 4.5 & 1.2 & 0.1 & 1.3 & 13.7 \\
\hline 1997 & 14.1 & 11.8 & 2.2 & 4.4 & 6.1 & 3.8 & 4.5 & 1.6 & 0.1 & 1.7 & 13.4 \\
\hline $1998^{c}$ & 14.0 & 11.4 & 2.7 & 4.4 & 6.0 & 3.5 & 4.0 & 2.0 & 0.1 & 2.1 & 12.5 \\
\hline
\end{tabular}

Fuente: Banco Central de Reserva del Perú (varios números).

a Sin ingresos de capital. b Con ingresos de capital.

Los bancos comerciales expandieron notablemente sus préstamos internos en dólares con fondos obtenidos en el exterior, justo cuando la autoridad monetaria intentaba imponer una restricción crediticia a través de una política de esterilización. ${ }^{53}$ La evidencia que demuestra que la banca comercial ha recurrido al mercado internacional de capitales para satisfacer la demanda interna de préstamos es contundente. En el cuadro 3 (columna pasivos internacionales como porcentaje del crédito en moneda extranjera) se pudo ver que el endeudamiento externo de corto plazo de la banca comercial se ha acrecentado rápidamente desde la crisis mexicana.

La banca comercial se ve estimulada a realizar este tipo de operaciones porque hay una diferencia apreciable entre el costo de estos fondos externos y la tasa de interés interna activa en moneda extranjera. Además, los depósitos internos en dólares están sujetos a un encaje alto (45\%), del cual están exentos los fondos externos. Así, la política de encajes de la autoridad monetaria fomenta el endeudamiento externo de corto plazo de la banca comercial.

De esta manera, si los banqueros locales creen que es razonable ampliar velozmente los préstamos, y si los mercados internacionales les proveen de los fondos para hacerlo, fácilmente puede desatarse un auge crediticio, pues la autoridad monetaria no cuenta con los medios que le permitan moderar esta excesiva expan-

\footnotetext{
${ }^{53}$ Esto es, colocando valores de corto plazo en los bancos y otras instituciones financieras, para esterilizar o contrarrestar la emisión resultante de la compra de dólares.
}

c Hasta el tercer trimestre.

sión del crédito bancario. ${ }^{54}$ Esto explica que el duro ajuste fiscal se haya combinado en 1995-1996 con una importante expansión del crédito, lo que enfrió la economía sin corregir mayormente el déficit comercial. ${ }^{55}$

Pero el fenómeno inverso - una contracción no deseada por la autoridad monetaria - también es posible. Si los mercados internacionales cortan de improviso los fondos con que abastecen al sistema bancario interno, puede gestarse una fuerte contracción que constituya un enorme impulso recesivo y que, simultáneamente, mejore la balanza comercial a través de una reducción de las importaciones.$^{56}$ Eso es lo que ocurrió en el tercer trimestre de 1998 a raíz de la crisis de balanza de pagos rusa.

Desde el estallido de la crisis asiática a mediados de 1997, la entrada global de capitales a la economía

${ }^{54}$ Puede aplicarse un encaje a los fondos que la banca comercial consigue en el exterior, similar al que recae sobre los depósitos internos en dólares, que permita recortar la oferta de crédito en moneda extranjera y encarecer su costo. Bajo condiciones razonables, puede argüirse que esta política crediticia restrictiva elevaría las tasas de interés activas, en soles y dólares, y también el tipo de cambio (véase Dancourt y Mendoza, 1996). Hasta hace poco, el Banco Central se resistió a imponer un encaje de esta clase, aduciendo que interfería con la libre movilidad de capitales y que afectaría la confianza de los inversionistas. En julio de 1998, la Superintendencia de Banca y Seguros creó un requisito mínimo de liquidez que cumple una funcion similar a este encaje.

55 Como porcentaje de las exportaciones, el déficit comercial pasó del 39\% en 1995 al $34 \%$ en 1996, mientras el tipo de cambio real se mantenía constante.

${ }^{56}$ Un ejemplo importante de este vínculo directo entre crédito e importaciones es el gasto en bienes durables, como automóviles y electrodomésticos, cuya producción nacional es inexistente. 
peruana disminuyó sensiblemente. Sin embargo, el mercado de crédito bancario interno en moneda extranjera siguió operando fluidamente, gracias a la continua expansión de los fondos que los bancos conseguían en el exterior.

A junio de 1998, la deuda externa total de corto plazo ascendía a 7323 millones de dólares, un monto equivalente al $70 \%$ de las reservas de divisas de la autoridad monetaria, o al $110 \%$ si excluimos de estas reservas los encajes de los depósitos internos en moneda extranjera. Alrededor de la mitad de esta deuda externa de corto plazo correspondería a la banca comercial, y el resto incluiría básicamente la deuda de corto plazo de las grandes empresas no financieras que, sin embargo, podría estar garantizada de una u otra forma por los bancos locales.

En septiembre, sin embargo, la economía peruana fue sacudida duramente por una fuerte salida de capitales originada por la cancelación o no renovación de las líneas de crédito de corto plazo que la banca comercial local venía obteniendo en el exterior. Esta suerte de corrida de los acreedores externos de los bancos locales, que aconteció por primera vez durante los años noventa, se produjo durante el pánico financiero causado por la crisis de balanza de pagos de Rusia.

Este brusco cambio de dirección de las corrientes de capital de corto plazo intermediadas por la banca comercial local causó un potente ataque especulativo contra la moneda nacional. Igual que en anteriores episodios en que se registraron fuertes presiones alcistas en el mercado cambiario, también esta vez el precio del dólar en moneda nacional se disparó, conjuntamente con la tasa de interés interbancaria en moneda nacional. La peculiaridad es que en esta ocasión también se incrementó apreciablemente la tasa interbancaria en moneda extranjera.

El Banco Central reaccionó frente a esta presión alcista sobre el tipo de cambio tomando medidas sin precedentes en los últimos años. La primera reacción consistió en intervenir en el mercado cambiario me- diante la venta de dólares, cosa que no hacía desde el autogolpe de abril de 1992. La segunda reacción consistió en otorgar "créditos de liquidez" (préstamos de corto plazo) en moneda extranjera a los bancos comerciales para que éstos pudieran pagar sus deudas de corto plazo con el exterior, oficiando en la práctica como prestamista de última instancia. Luego, rebajó por tres veces consecutivas la tasa de encaje media sobre los depósitos en dólares de los bancos comerciales, también para que los bancos pudieran pagar sus deudas de corto plazo.

Finalmente, el Banco Central, la Superintendencia de Banca y Seguros y el gobierno mismo tomaron otras dos medidas mucho menos ortodoxas para frenar el alza del tipo de cambio. De un lado, se decretó la conversión de los depósitos bancarios del sector público de moneda extranjera a moneda nacional, una suerte de desdolarización forzosa del sector público. Estos depósitos podrían representar una cuarta parte de los depósitos totales. Del otro lado, se limitó la "sobrecompra" de dólares por parte de los bancos y otras instituciones financieras hasta un monto equivalente a su patrimonio efectivo.

El pánico de septiembre de 1998 parece haber inaugurado una nueva época de escasez de crédito interno en moneda extranjera. Según el presidente de la Asociación de Bancos, la menor disponibilidad y el incremento del costo de las líneas de crédito del exterior afectarán a los créditos hipotecarios y para adquisición de vehículos automotores, a las tarjetas de crédito, y a los créditos de consumo (Gestión, 1998). Y todo indica que esta dura restricción crediticia en moneda extranjera podría tener un gran impacto negativo sobre las ventas de bienes de consumo duraderos, las importaciones, la industria de la construcción, y los precios de casas y terrenos, además de amenazar la estabilidad del sistema bancario local. Si algo está claro, es que la expansión del crédito ha sido el elixir que ha mantenido lozana a la economía del Perú durante los últimos años.

\section{VII}

\section{A modo de conclusión}

En el Perú, la estrategia neoliberal consiste en retornar al modelo de desarrollo basado en las exportaciones de materias primas. Esta empresa, que intenta reinventar los años cincuenta a fines de los noventa, se enfrenta naturalmente a diversos obstáculos.
El primer obstáculo es el que podríamos denominar sociopolítico. Acéptese que las reformas estructurales de Fujimori pueden reimplantar exitosamente el modelo primario exportador que imperó durante 19501960. Aun así, habría que tomar en cuenta el desajus- 
te que el alto grado de urbanización introduce entre la estructura social actual y la estrategia primario-exportadora.

Seminario (1995) ha subrayado esta contradicción. "El punto de partida del último intento liberal es el rasgo original de este experimento económico: una economía esencialmente urbana. En el pasado, las economías exportadoras se edificaron sobre una población mayoritariamente rural, gran abundancia de recursos naturales en relación a la población y escaso desarrollo industrial". Según los censos de población, la participación de la población urbana en la población subió desde $35 \%$ en 1940 hasta $70 \%$ en 1993.

Es difícil que una economía exportadora de minerales genere suficientes puestos de trabajo en una sociedad urbanizada, como demuestra la propia experiencia peruana. Esto implica que el desempleo, disfrazado o no, será uno de los problemas socioeconómicos cruciales. En consecuencia, habrá presión política por desarrollar actividades económicas que lo resuelvan. Como ha argumentado Schydlowsky (1995), ésta fue una de las vías que condujeron hacia la industrialización y el proteccionismo.

Para tener un aparato productivo más diversificado, habría que reforzar la situación de la industria interna expuesta a la competencia internacional, y promover las exportaciones no tradicionales (incluido el turismo). Esto supone revertir en algún grado la apertura comercial, así como corregir la sobrevaluación cambiaria. Y probablemente implique también que la economía peruana se integre firmemente en la Comunidad Andina, obteniendo así acceso preferencial a un gran mercado.

La apreciación cambiaria mencionada parecería implicar una incoherencia, porque la reforma neoliberal propugna una estrategia de crecimiento proexportadora. Sin embargo, este tipo de cambio real bajo sólo es incompatible con el desarrollo de exportaciones industriales o, quizás, de exportaciones agroindustriales al estilo chileno, o del turismo a gran escala. No es necesariamente incompatible con las exportaciones de materias primas que han jalonado la historia económica del Perú. Todo depende de la calidad de los recursos naturales existentes y de la tecnología disponible.

En realidad, el problema podría plantearse exactamente al revés. Si descartamos cambios mayores en el nivel de actividad económica o en la propensión a importar, la única vía para validar en el mediano plazo este tipo de cambio real, que está asociado a un déficit comercial superior al $30 \%$ del valor exportado en el ultimo trienio, es una gran expansión de estas exportaciones tradicionales. La cuestión entonces es saber, primero, si se han puesto en marcha suficientes proyectos de inversión en esta área de exportación tradicional (minería, especialmente) y, segundo, si estos proyectos madurarán oportunamente. Es decir, antes de que se reduzca la entrada de capitales externos, que financia el déficit comercial y los pagos netos por deuda externa pública y que sostiene ese tipo de cambio real sobrevaluado.

Está claro que esta es una situación frágil o vulnerable. Ante shocks externos adversos que reduzcan la entrada de capitales foráneos, o que disminuyan los precios de las materias primas y posterguen la maduración de los proyectos de inversión en curso, puede generarse una crisis de balanza de pagos, si la respuesta de política macroeconómica no es la adecuada. (Un componente esencial de la crisis acaecida en 1975 bajo el gobierno militar de Velasco Alvarado fue el retraso de la entrada en explotación de dos grandes proyectos minero-petroleros.)

Desde mediados de 1997, como tantas otras veces en su historia, la economía peruana sufre el impacto de un shock externo adverso apreciable que afecta simultáneamente tanto a la cuenta corriente como a la cuenta de capital de la balanza de pagos. Los precios de las materias primas de exportación han descendido notablemente desde el estallido de la crisis asiática a mediados de 1997, provocando una fuerte caída de la relación de precios del intercambio, a pesar de que el índice de precios en dólares de las importaciones también se ha reducido.

Al mismo tiempo, la entrada global de capitales ha disminuido sensiblemente desde 1997. Esta paralización de la afluencia de capitales externos abarca tanto a los de largo plazo (inversión directa vinculada a la privatización o a los megaproyectos mineros, que iban a ampliar significativamente la capacidad productiva en el sector exportador), como a los capitales de corto plazo (endeudamiento externo de la banca comercial) desde mediados de 1998.

¿Qué políticas macroeconómicas son las adecuadas para enfrentar una coyuntura económica internacional desfavorable? Esta pregunta nos conduce al otro obstáculo importante que enfrenta la estrategia neoliberal, que es el que podríamos denominar macroeconómico. La hipótesis central de este artículo es que la economía peruana de los años noventa carece de un modo de regulación macroeconómico operativo, que funcione sin producir grandes trastornos del nivel de actividad económica. 
En particular, se ha puesto de relieve que la autoridad monetaria no cuenta con los instrumentos básicos que normalmente se han usado para manejar, con relativo éxito, los shocks externos adversos a los que está expuesta, inevitablemente, una economía pequeña y abierta. La política monetaria ha perdido eficacia como resultado de dos reformas estructurales rea- lizadas en el ámbito financiero: la dolarización del sistema bancario y la apertura de la cuenta de capitales.

Superar el primer obstáculo equivale a modificar el modelo primario-exportador, quizás hasta hacerlo irreconocible. Superar el segundo es una tarea urgente, pero quizá menos complicada.

\section{Bibliografía}

Banco Central de Reserva del Perú (varios números): Nota semanal, Lima.

(1995): Memoria 1994, Lima.

(1996): Perú: compendio de estadísticas monetarias 1959-

1995, Lima. (1998): Memoria 1997, Lima.

Borricaud, F. (1989): Poder y sociedad en el Perú, Lima, Instituto de Estudios Peruanos.

Calvo, G., L. Leiderman y C. Reinhart (1993): Capital inflows and real exchange rate appreciation in Latin America, Staff Papers, vol. 40, $\mathrm{N}^{\circ}$ 1, Washington, D.C., Fondo Monetario Internacional (FMI).

Cline, W. (1981): Economic stabilization in Peru, 1975-1978, W. Cline y S. Weintraub (eds.), Economic Stabilization in Developing Countries, Washington, D.C., The Brookings Institution.

Cotler, J. (1994): Política y sociedad en el Perú: cambio y continuidades, Perú problema, $\mathrm{N}^{\circ}$ 3, Lima, Instituto de Estudios Peruanos.

Dancourt, O. (1996): Estabilización y deuda externa en el Perú: experiencia y perspectivas, G. Portocarrero y M. Valcarcel (eds.), El Perú frente al siglo XXI, Lima, Pontificia Universidad Católica del Perú (PUCP).

Dancourt, O. y W. Mendoza (1996): Flujos de capital, política monetaria y equilibrio externo, Documento de trabajo, $\mathrm{N}^{\circ} 126$, Lima, PUCP, Departamento de Economía.

Dancourt, O., W. Mendoza y L. Vilcapoma (1997): Fluctuaciones económicas y shocks externos, Perú 1950-1996, Documento de trabajo, $\mathrm{N}^{\circ} 135$, Lima, PUCP, Departamento de Economía.

Fairlie, A. (1996): Comunidad andina, regionalismo abierto y comercio intraindustrial, en El Protocolo de Trujillo y la Comunidad Andina, Política internacional, $\mathrm{N}^{\circ} 43$, Lima, Academia Diplomática del Perú.

Ferrari, C. (1992): Industrialización y desarrollo: políticas y efectos económicos en el Perú, Lima, Fundación Friedrich Ebert.

Figueroa, A. (1993): Crisis distributiva en el Perú, Lima, PUCP.

Fitzgerald, E.V.K. (1985): Capitalismo de Estado en el Perú: limitaciones de un modelo de desarrollo económico, El gobierno militar: una experiencia peruana 1968-1980, Lima, Instituto de Estudios Peruanos.

Frenkel, R., J.M. Fanelli y G. Rozenwurcel (1993): Growth and Structural Reform in Latin America. Where We Stand, Discussion papers, $\mathrm{N}^{\circ}$ 62, Ginebra, Conferencia de las Naciones Unidas sobre Comercio y Desarrollo (UNCTAD).

Gavin, M., R. Hausmann, R. Perotti y E. Talvi (1997): El manejo de la política fiscal en América Latina y el Caribe, Revista $B C V$, vol.XI, $\mathrm{N}^{\circ} 1$, Caracas, Banco Central de Venezuela.

Gestión (1998): Edición del 12 de octubre de 1998, Lima.

González, E. (1994): Ajuste estructural y reforma de la economía fiscal en el Perú, serie Documentos de Trabajo Nº64, Lima, Instituto de Estudios Peruanos.
Hofman, A. (1993): Economic development in Latin America in the 20th century. A comparative perspective, A. Szirmai, B. Van Ark y D. Pilat (eds.), Explaining Economic Growth. Essays in Honour of Angus Maddison, Amsterdam, Países Bajos, North-Holland.

Hunt, S. (1996): Peru: The current economic situation in long-term perspective, E. Gonzáles de Olarte (ed.), The Peruvian Economy and Structural Adjustment: Past, Present, and Future, Miami, Florida, University of Miami, North-South Center Press.

Iguíñiz, J. (1986): La crisis peruana actual: un esquema para una interpretación, H. Bonilla (ed.), Las crisis económicas en la historia del Perú, Lima, Centro Latinoamericano de Historia Económica y Social/Fundación Friedrich Ebert.

Jiménez, F. (1991): Acumulación y ciclos en la economía peruana: crisis de paradigmas y estrategia de desarrollo neoliberal, Lima, Centro de Estudios para el Desarrollo y la Participación (CEDEP).

(1996): Notas sobre la desindustrialización reciente y la necesidad de una nueva política industrial, Socialismo y participación, $\mathrm{N}^{\circ} 74$, Lima, CEDEP.

Krugman, P. (1988): External shocks and domestic policy responses, R. Dornbusch y F.I. Helmers (eds.), Open Economy. Tools for Policymakers in Developing Countries, Washington, D.C., Oxford University Press.

Krugman, P. y L. Taylor (1978): Contractionary effects of devaluation, Journal of International Economics, vol. 8, $\mathrm{N}^{\circ} 3$, Amsterdam, Países Bajos, North-Holland Publishing Company.

Maddison, A. (1991): Dynamic Forces in Capitalist Development: A Long Run Comparative View, Oxford, Reino Unido, Oxford University Press.

(1992): La economía mundial en el siglo XX. Rendimiento y política en Asia, América Latina, la URSS y los países de la $O C D E$, México, D.F., Fondo de Cultura Económica (FCE).

Marfán, M. y B. Bosworth (1994): Saving, investment, and economic growth, B. Bosworth, R. Dornbusch y R. Labán (eds.), The Chilean Economy. Policy Lessons and Challenges, Washington, D.C.,The Brookings Institution.

Paredes, C. y J. Sachs (eds.) (1990): Estabilización y crecimiento en el Perú, Lima, Grupo de Análisis para el Desarrollo (GRADE).

Robles, M. (1996): Los ciclos económicos en el Perú: 1950-1995, Lima, Instituto Nacional de Estadística e Informática.

Rojas, J. (1996): Políticas comerciales y cambiarias en el Perú, 1960-1995, Lima, PUCP.

Rojas, J. y L. Vilcapoma (1996): Algunas características importantes de la nueva Banca Peruana: un estudio preliminar, Documento de trabajo, $\mathrm{N}^{\circ} 124$, Lima, PUCP, Departamento de Economía.

Rossini, R. (1991): Liberalización comercial y estabilización económica, Foro económico liberalización del comercio exterior, Lima, Fundación Friedrich Ebert. 
Ruiz, G. (1995): Apreciación cambiaria, política monetaria y afluencia de capitales: Perú 1990-1994, Economía, vol. XVIII, N³5-36, Lima, PUCP, Departamento de Economía.

Schuldt, J. (1994): La enfermedad holandesa y otros virus de la economía peruana, Documento de trabajo, $\mathrm{N}^{\circ} 20$, Lima, Universidad del Pacífico, Centro de Investigación.

Schydlowsky, D. (1986): The macroeconomic effect of nontraditional exports in Peru, Economic Development and Cultural Change, vol. 34, $\mathrm{N}^{\circ} 3$, Chicago, Illinois, The University of Chicago Press.

(1995): La recuperación económica peruana en contexto histórico, Lima.

Schydlowsky, D. y J. Wicht (1979): Anatomía de un fracaso económico: Perú 1968-1978, Lima, Universidad del Pacífico, Centro de Investigación.

Seminario, B. (1995): Reformas estructurales y políticas de estabilización, Documento de trabajo, $\mathrm{N}^{\circ} 22$, Lima, Universidad del Pacífico, Centro de Investigación.

Seminario, B. y C. Boullon (1992): Ciclos y tendencias en la economía peruana: 1950-1989, Cuadernos de investigación, $\mathrm{N}^{\circ} 15$, Lima, Universidad del Pacífico, Centro de Investigación.

Taylor, L. (1991): Economic openness: Problem to the century ends, T. Banori (ed.), Economic Liberization: No Panacea, Oxford, Reino Unido, Oxford University Press.
Terrones, M. y C. Calderón (1993): El ciclo económico en el Perú, Documentos de trabajo, $\mathrm{N}^{\circ}$ 20, Lima, GRADE.

Thorp, R. (1995): Gestión económica y desarrollo en Perú y Colombia, Lima, Universidad del Pacífico.

(1996): A Long-Run Perspective on Short-Run Stabilization, E. Gonzales de Olarte (ed.), The Peruvian Economy and Structural Adjustment: Past, Present, and Future, Miami, Florida, University of Miami, North-South Center Press.

Thorp, R. y G. Bertram (1978): Perú 1890-1977: Growth and Policy in an Open Economy, Nueva York, Columbia University Press.

Ugarteche, O. (1996): La deuda peruana a fines de siglo, Lima, CEDEP.

(1997): Deuda externa: el fin de la historia, Revista actualidad económica, $\mathrm{N}^{\circ} 175$, Lima, Centro de Asesoría Laboral del Perú (CEDAL).

Vega, J. (1997): Foreign trade policy and economic integration policy in Peru: Analysis of a dilemma, A.J. Jatar y S. Weintraub (eds.), Integrating the Hemisphere, Washington, D.C., InterAmerican Dialogue Conference.

Vega-Centeno, M. (1989): Inversiones y cambio técnico en el crecimiento de la economía peruana, Economía, vol. XII, $\mathrm{N}^{\circ} 24$ Lima, PUCP, Departamento de Economía.

Vilcapoma, L. (1996): Fluctuaciones macroeconómicas en la economía peruana; 1950-1990, Documento de trabajo, $\mathrm{N}^{\circ} 130$, Lima, PUCP, Departamento de Economía. 